\title{
Ageing of lime mortars with admixtures: durability and strength
}

\section{assessment}

\author{
A. Izaguirre ${ }^{a}$, J. Lanas ${ }^{b}$, J.I. Álvarez ${ }^{a, *}$ \\ ${ }^{a}$ Department of Chemistry and Soil Sciences, School of Sciences, University of Navarra, c/ Irunlarrea, 1, \\ 31008, Pamplona, Spain \\ ${ }^{b}$ CTH Navarra, Polígono Talluntxe II C/M, 10, 31192, Tajonar, Spain
}

$\mathbf{N}^{0}$ of pages: 53

$\mathbf{N}^{\mathbf{0}}$ of tables: 6

$\mathbf{N}^{0}$ of figures: 21

Keywords: D. Admixture; C. Durability; C. Sulfate attack; Lime mortar

*Dr. Jose I. Alvarez Galindo

Dpto. de Química

Fac. de Ciencias

Universidad de Navarra

$\mathrm{C} /$ Irunlarrea, 1

31.080 Pamplona (Navarra)

Spain

Phone: 34948425600

Fax: 34948425649

E-mail: jalvarez@unav.es 


\title{
Ageing of lime mortars with admixtures: durability and strength
}

\section{assessment}

\author{
${ }^{\mathrm{a} A}$. Izaguirre, ${ }^{\mathrm{b}} \mathrm{J}$. Lanas, ${ }^{\mathrm{a} J . I . ~ A ́ l v a r e z ~}{ }^{*}$ \\ ${ }^{a}$ Department of Chemistry and Soil Sciences, School of Sciences, University of Navarra, c/ Irunlarrea, 1, \\ 31008, Pamplona, Spain \\ ${ }^{b}$ CTH Navarra, Polígono Talluntxe II C/M, 10, 31192, Tajonar, Spain
}

\section{Abstract}

Lime-based mortars modified with admixtures were prepared and subjected to different environments such as outdoor and indoor exposures, climatic chamber, $\mathrm{SO}_{2}$-chamber, and freezing-thawing cycles. The influence that the different admixtures (water repellents, water retainers, polypropylene fibre and a viscosity modifier) had on the pore size distribution of the hardened specimens was assessed and related to the water absorption capacity, and hence to the durability. Ageing resistance and mechanical strengths improved when additives reduced the water intake and increased the aircontent. High dosages of water repellents were necessary to enhance the durability, sodium oleate being the most effective additive to endure freezing processes. Also the low tested dosage of fibre, a water retainer (guar gum derivative), and a starch proved to be useful. $\mathrm{SO}_{2}$ deposition caused the formation of calcium sulphite hemihydrate as the main degradation product. A very small amount of calcium sulphate dihydrate was observed. A crystal habit composed of acicular agglomerates of calcium sulphite hemihydrate was detected in $\mathrm{SO}_{2}$ deposition on calcareous materials. 


\section{Introduction}

There has recently been increased scientific interest in lime-based mortars and their uses, as they show greater compatibility with ancient building materials and fulfil the recommendations of ICCROM [1] about the use of materials similar to the original ones in repair work [2-5]. Furthermore, they have been widely used in modern work with decorative and protective purposes (renders and facades) $[6,7]$. Both uses require the mortars to be durable, especially when they are directly exposed to environmental conditions, as their performance and aesthetic characteristics could become affected $[6$, $8]$.

Different deterioration factors can affect the durability of a mortar. Some of the most important ones could be included in the following main groups: i) wet and dry cycles; ii) rain exposure and related leaching; iii) freezing and thawing cycles; iv) exposure to pollutants (such as $\mathrm{SO}_{2}$ ); and v) sun's rays. The extent to which a mortar is affected by these deterioration factors is a function of the mortar's properties, which depend, in turn, on several issues, such as the kind and characteristics of the binder and the aggregate, the binder/aggregate ratio, the amount of mixing water, the mortar's permeability [9-12], the water absorption capacity through capillarity $[10,13]$, water intake $[7,14,15]$, the presence of admixtures and the curing conditions [16-18].

$\mathrm{SO}_{2}$ exposure is supposed to affect the mortars because gaseous $\mathrm{SO}_{2}$ has been widely reported to react with calcium carbonate, giving rise to the formation of both calcium sulphite hemihydrate $\left(\mathrm{CaSO}_{3} \cdot 1 / 2 \mathrm{H}_{2} \mathrm{O}\right)$ and calcium sulphate dihydrate $\left(\mathrm{CaSO}_{4} \cdot 2 \mathrm{H}_{2} \mathrm{O}\right)$ on the mortar's surfaces $[6,8,19-21]$. Calcium sulphite has been considered to be the 
most important product obtained under certain circumstances, such as the absence of catalyst [21,22]. It also acts as an intermediate product, because its oxidation gives rise to calcium sulphate formation $[21,23,24]$. Calcium sulphate dihydrate appears as the most important product of decay in carbonated materials when suitable catalysts are present [23]. Several factors affecting $\mathrm{SO}_{2}$ deposition have been discussed by Cultrone et al. [20].

The formation of calcium sulphite hemihydrate and calcium sulphate dihydrate becomes an important factor in deterioration when rain is involved in the decay process, as these salts can dissolve in water and be washed away from the surface. As a result, the cementing material is weakened and the specimens are degraded [6].

Several previous studies pointed to the significance of the chemical composition for the mortar's durability [6,8,20,25-27], while air content, porosity, pore structure, permeability and water absorption through capillarity have been quoted as essential factors affecting the durability of a mortar [28]. Admixtures can be useful in order to improve these properties and to obtain better performance from the lime mortar. These consist of substances added in percentages lower than $5 \%$ with the purpose of improving certain mortar properties.

In spite of the importance of additives in cement mortars or concrete, very few publications have so far focused on the changes in durability that additives may cause in aerial lime-based mortars, and no references to mechanical strength assessment can be found. The present research has been carried out with the aim of broadening our knowledge of the durability of aerial lime mortars modified with different additives and 
assessing their mechanical behaviour when they are subjected to several different ageing processes.

In this paper, water repellents were chosen because they are supposed to increase the mortar's durability by hindering water intake, thus avoiding any related problems. Two water-repelling agents, calcium stearate and sodium oleate, were added and tested. Their effects on the rheological and hardened properties of lime-based mortars had been previously researched [29]. A fibre reinforcement was tested because it was expected to improve mechanical strengths and shrinkage, which are weak points in aerial lime-based mortars [30]. The selection of a polypropylene fibre is based on its efficiency as well as to its great cost-effectiveness for cement mortars $[19,22]$. The water retaining products were added as they are supposed to improve the homogeneity of the mixture, enhancing the workability of the mortar and some of the properties in the hardened state $[1,8]$. Two different commercial water-retaining agents were used: hydroxypropyl methylcellulose, widely used in cement mortars, and a guar gum derivative (hydroxypropylguar), which is used in dietetics and pharmacy due to its high water retention capacity, although its potential as admixture for mortars has received scant attention [10,11]. Finally, the rationale for the use of a starch derivative is that its water-reducing action could be desirable in lime-based mortars to avoid large amounts of mixing water that could slow down the carbonation process. Furthermore, the expected thickening effect of the starch is supposed to give non-sag and anti-slip properties to the mixtures. In addition, the starch derivative, a biodegradable polymer, is an environmentally friendly alternative to the traditional sulphonated formaldehyde condensates or polycarboxylate-type plasticizers. 
In short, this paper presents a systematic study of the ageing characteristics of aerial lime-based mortars modified with the incorporation of the aforesaid admixtures. Hardened mortars are exposed to several environments (indoor exposure, outdoor exposure, climatic chamber, $\mathrm{SO}_{2}$ chamber and freezing-thawing cycles) and their degree of alteration, weight change and mechanical strengths are evaluated after several times of exposure. The influence that each additive exerts on mortar properties, especially on its pore size distribution, and, as a consequence, on its durability, is reported. This assessment will allow us to draw conclusions about the usefulness of these admixtures when added to lime-based mortars for repair purposes.

\section{Materials}

An aerial commercial lime and a pure limestone aggregate were used to prepare the mortars. The lime (class CL 90-S according to Spanish standard [31]) was supplied by Calinsa (Navarra). The aggregate was supplied by Caleras de Liskar (grupo HORPASA), and was a calcareous type. Materials' characterization as well as their grain size distribution have previously been reported [29]. Mortars were prepared by mixing $341.7 \mathrm{~g}$ of the lime and $1286.9 \mathrm{~g}$ of the aggregate, meaning a 1:1 volume ratio. Six different additives were tested, and were incorporated to the mixtures individually in order to check clearly the influence that each one of them exerted on mortar durability. These selected additives were: i) two different water-repelling agents: sodium oleate (SO) from ADI-center S.L.U. (HISA-A $2388 \mathrm{~N}^{\circledR}$ )and calcium stearate (CS) from Mateos S.L. (ETP-09 $\left.{ }^{\circledR}\right)$; ii) two different water-retaining agents: hydroxypropylmethylcellulose (HPMC) from Hercules (HPMC HK $15 \mathrm{M}^{\circledR}$ )and a guar gum derivative (hydroxypropylguar) (HPG) from Lamberti Quimica S.A. (ESACOL 
HS-30 ${ }^{\circledR}$ ); iii) a polypropylene fibre (PP) from FOSROC (Fibricete $600^{\circledR}$ ); and iv) a potato starch polymer (PS) from AVEBE (OPAGEL CMT ${ }^{\circledR}$ ). Table 1 shows the amount of admixture of each mortar sample. Mixing water ranged from 1.17 water/binder ratio to 1.55 , following a workability criterion. The amount of mixing water has a major influence on the final properties of the mortar, because it conditions the porosity. A control group (plain mortar) was included in order to assess any change.

\section{Methods}

\subsection{Mortar preparation}

Lime, aggregate and additive, if necessary, were blended for 5 minutes using a solid mixer BL-8-CA (Lleal S.A.). Water was then added and mixed for 90 seconds at low speed, in a Proeti ETI 26.0072 mixer. Mortars were moulded in prismatic 40x40x160 $\mathrm{mm}$ casts, stored at $\mathrm{RH} 60 \%$ and $20^{\circ} \mathrm{C}$, and demolded 5 days later [32]. Mortars were compacted in a specific automatic compactor for 60 seconds. Curing was executed in ambient laboratory conditions for 56 days (RH at ca. $60 \%$ and temperature around $20^{\circ} \mathrm{C}$ ). Table 2 summarizes results of air content, capillarity coefficient and permeability coefficient obtained for the mortars [33-35].

After the curing process, the samples were subjected to five different environments and tested after 5 different times of exposure: 2, 7, 14, 21 and 28 days. Two specimens were tested at each time, and the reported results are an average of the obtained results. 50 samples were prepared for each mortar, so 500 specimens were prepared in total. 


\subsection{Environments of exposure}

After 56 days of hardening in ambient laboratory conditions, samples were placed in different environments:

i) ambient laboratory conditions: $\mathrm{RH} 60 \pm 10 \%$ and $20 \pm 5^{\circ} \mathrm{C}$, as a control group.

ii) outside exposure, i.e., samples were exposed on a platform in a piece of open ground without shelter, subjected to climatic events.

iii) climatic chamber, using a CCI FCH-XENOLAB 1500 chamber with different conditions of temperature $(\mathrm{T})$, relative humidity $(\mathrm{RH})$, ultraviolet light and rain. Table 3 shows the characteristics of the set cycles.

iv) freezing-thawing cycles, using a CARAVELL 521-102 freezer. The cycles consisted of a water immersion of the samples and, straight afterwards, freezing at $-10^{\circ} \mathrm{C}$ for 24 hours.

v) $\mathrm{SO}_{2}$ rich environment, using a $\mathrm{SO}_{2}$ chamber (Kesternich chamber). The selected cycles included a $\mathrm{SO}_{2}$ addition of $2 \mathrm{~L}$ in the whole volume of the chamber $(300 \mathrm{~L})(0.67 \%$ in percentage volume/volume $)$. More details on the experimental set up can be found in the work by Lanas et al. [8].

\subsection{Alteration study}

The durability of the tested specimens was studied by means of weight change, qualitative evaluation and compressive strength. In order to evaluate any modification in the chemical or mineralogical composition of the samples, FTIR spectroscopy analyses 
(performed with a Nicolet-FTIR Avatar 360 spectrometer, using a MKII Golden Gate ATR device; resolution: $2 \mathrm{~cm}^{-1}$, spectrum obtained as an average of 100 scans), X-ray diffraction studies (carried out by means of a Bruker D8 Advance with a Goëbel mirror, which allowed to perform experiments directly on the sample's surface, CuKa1 radiation, $0.02^{\circ} 2 \theta$ increment and $1 \mathrm{~s} . s t e p^{-1}$ ), thermogravimetric analyses (performed with a simultaneous TG-sDTA 851 Mettler Toledo, using alumina crucibles, at $20^{\circ} \mathrm{C}$ $\min ^{-1}$ heating rate, from ambient temperature to $1200^{\circ} \mathrm{C}$ ) were executed. Also pore size distribution assessment (by using a Micromeritics AutoPore IV 9500 with a range of pressure between 0 and $207 \mathrm{MPa}$ ) was carried out. The qualitative evaluation was visually determined, using a previously reported criterion [8], which attributes degree 0 of alteration for samples without evidence of decay; degree 1 for slightly altered samples, with some thin and short cracks at the surface of the specimens; degree 2 for altered samples, showing several deeper cracks (like spider's web); degree 3 for very altered specimens having deep cracks and undergoing swelling; degree 4 for a high decay, large and deep cracks, large swelling of the specimen and a partial weight loss; and, finally, degree 5 for completely destroyed samples, with only parts of it remaining.

Microstructure of samples exposed to $\mathrm{SO}_{2}$-chamber was analysed by means of scanning electron microscopy, with a Digital Scanning Microscopy Philips XL 30CP with EDS/EDAX Phoenix.

\section{Results and discussion}

\subsection{Mortars with water-repelling agents}


All the tested mortars tended to increase their weight when subjected to rain exposure or water immersion, which means that they absorbed water. The sample with sodium oleate in a high dosage showed great water-repelling capacity, as can be confirmed with reference to the degree of alteration of samples after freezing-thawing cycles (Table 4). In a previous study by our research group [29] mortars with high dosage of sodium oleate showed no sign of deterioration after freezing-thawing cycles. In the present study, the tests carried out on samples with different water repellent dosages showed that when specimens were modified with lower dosages of admixtures, they were destroyed after some cycles (Fig. 1). The most significant compressive strength results for the studied mortars are shown in Fig. 2. As a general statement, the larger the visual alteration, the lower the mechanical strengths (Figs. 1 and 2b)).

As reported in our previous study, when additives were added at low dosage, the amount of mixing water was quite similar to that for the control mortar. Owing to the increase in small particles when high dosages of additives were used, the mixing water that mortar needed to fulfil the set slump values was larger. In spite of the fact that larger water/binder ratio could lead to a porosity increase, these samples showed no increment in the large pores, as previously reported [29]. It has been found that the rise in mixing water did not involve any drawback regarding the durability behaviour of these mortars, as will be discussed below.

Capillarity coefficients of the mortars (Table 2) can explain the observed behaviour: as the water absorption through capillarity increased, the durability of the material subjected to water contact worsened (climatic chamber exposure and freezing-thawing cycles in Fig. 2). As a way to assess the water absorption, the weight evolution was determined (Fig. 3a shows as an example the weight variation in samples subjected to climatic chamber), confirming that high dosages of both water repellents led to 
reduction of the water absorption, and matching previous results about capillarity and the degree to which the sample decayed. At low dosages, only sodium oleate clearly reduced the amount of absorbed water. The differences in the behaviour of the two tested water-repelling agents were explained in the aforementioned study, and related to solubility and adsorption differences between sodium oleate and calcium stearate, which gave rise to a different quantity of air voids and, therefore, to different capillarity coefficients [29].

Although $\mathrm{SO}_{2}$ deposition has been reported to result in the end loss of material, in the current study, cycles in $\mathrm{SO}_{2}$ chamber did not include any step with rain, so dragging of the calcium salts and the subsequent loss of material were not likely to occur. In fact, the tested mortars with water repellents showed a weight increase after $\mathrm{SO}_{2}$ exposure (Fig. 3b), which could be related to the formation of calcium sulphite hemihydrate or calcium sulphate dihydrate and to transformation of portlandite into calcite. As an example, Fig. 4 shows, among others, the IR spectra of a superficial layer of samples with sodium oleate in high dosage after 28 cycles in a $\mathrm{SO}_{2}$ chamber and after the same time in room conditions. It can be observed that $\mathrm{SO}_{2}$ exposure produced the appearance of calcium sulphite hemihydrate on the specimens' surface. Absorption bands at 990, 947 and $652 \mathrm{~cm}^{-1}$ indicate its presence [36]. Absorption bands related to the presence of calcium sulphate dihydrate are negligible. This fact can be explained by the absence of a catalyst in the experimental exposure, so that the calcium sulphite was the main degradation product. Only studies carried out on the sample's surface by X-ray diffraction analysis (see section 3.3) showed, in some specimens, diffraction peaks attributed to calcium sulphate dihydrate (Fig. 5). Such a small amount of gypsum 
hindered its identification by IR spectroscopy and pointed to the fact that only a limited oxidation of calcium sulphite hemihydrate took place.

On the other hand, cycles in $\mathrm{SO}_{2}$ chamber were characterized by a high relative humidity, so the carbonation process should have been improved, because water could condense into the pores, allowing the calcium hydroxide and the gaseous $\mathrm{CO}_{2}$ to dissolve and form calcium carbonate $[37,38]$. When the carbonation rate is improved, the mechanical properties of lime-based mortars are supposed to increase [2].

By means of thermogravimetric analysis, a reduction in the amount of calcium hydroxide could be determined in samples exposed to the $\mathrm{SO}_{2}$-chamber (Table 5: the loss of hydroxyl water of $\mathrm{Ca}(\mathrm{OH})_{2}$, which took place at ca. $450^{\circ} \mathrm{C}$, was used to determine the amount of calcium hydroxide on the TG curve) [38]. This drop was related to the enhancement in the carbonation process. Fig. 6 shows, as an example, pore size distribution for samples of sodium oleate at a high dosage, after being exposed to room conditions and sulphur dioxide chamber. Pore size distribution studies showed that, after 28 days of $\mathrm{SO}_{2}$ exposure, mortars achieved a narrower unimodal distribution: the peak related to $0.83 \mu \mathrm{m}$ pores became stronger (in the pore range of the main peak $-0.5-2 \mu \mathrm{m}$ - the percentage of total intrusion volume increased from 54\% - sample exposed to indoor conditions - to $90 \%$ - sample exposed to $\mathrm{SO}_{2}$-chamber) while the rest of small peaks almost disappeared (at 4.9, 2.5 and 0.03 $\mu \mathrm{m}$ ) (as a quantitative evaluation, the percentage of total intrusion volume from 2 to 10 $\mu \mathrm{m}$ suffered a reduction from $6.9 \%$ of sample in room conditions to $1.4 \%$ of $\mathrm{SO}_{2}$ exposed sample. In the pore range $0.01-0.1 \mu \mathrm{m}$, the percentage changed from $9.2 \%$ to $0 \%$ ). The calcite matrix is characterized by a unimodal pore size distribution centred on 
a value slightly below $1 \mu \mathrm{m}[39,40]$, so the modification of pores generated during the $\mathrm{SO}_{2}$ exposure agreed with the other data: transformation of portlandite into calcite was enhanced during the cycles. The carbonation of $\mathrm{Ca}(\mathrm{OH})_{2}$ caused the plugging of the largest and smallest pores, owing to the volume change, as the percentages of total intrusion volume for pore ranges of $2-10 \mu \mathrm{m}$ and $0.01-0.1 \mu \mathrm{m}$ proved. This fact may justify the pore size distribution modifications rather than sulphation phenomenon, which only took place on the surface of the samples and to a limited extent (Fig. 7 shows IR spectra and XRD results carried out on the superficial layer of the sample and on the inner part of the mortar. IR absorption bands and diffraction peaks related to calcium sulphite hemihydrate were found only on the superficial layer. This fact, together with their low intensity, confirms the limited and superficial phenomenon of the $\mathrm{SO}_{2}$-deposition). This improvement in carbonation process can be responsible for the observed increase in mechanical strengths during the performed cycles (Fig. 2c).

SEM-EDAX analyses showed that sodium oleate and calcium stearate samples were covered by products from $\mathrm{SO}_{2}$ deposition. Fig. 8 shows agglomerates of acicular crystals. It may be suggested that they are calcium sulphite hemihydrate, taking into account the facts that (i) FTIR and XRD showed the presence of calcium sulphite hemihydrate as a result of the $\mathrm{SO}_{2}$ deposition; (ii) previous publications reported many different shapes for calcium sulphate crystals obtained after $\mathrm{SO}_{2}$ exposure of calcareous materials $[8,20]$, but none of them had the observed shape; (iii) EDAX analysis showed that these crystals were made of sulphur, calcium and oxygen atoms; and (iv) Chen et al. [41] obtained agglomerates of acicular crystals of calcium sulphite hemihydrate from crystallization studies performed at high calcium concentrations and low $\mathrm{pH}$, their shape being identical to the crystals in Fig. 8. Such a crystal habit has so far not been reported 
as being formed as a result of $\mathrm{SO}_{2}$ deposition on lime-based or calcareous materials. Some previous work showed crystal shapes belonging to calcium sulphate crystals [8, 20] and other studies presented calcium sulphite hemihydrate crystals with rough spherical and platelet forms $[42,43]$. In the present study, it seems that the addition of surfactant molecules (water-repelling admixtures) to the mortar favoured the formation of agglomerates of acicular calcium sulphite hemihydrate crystals.

Fig. 8 shows that mortars modified by sodium oleate addition showed a higher amount of agglomerates of acicular calcium sulphite hemihydrate, while mortars modified by calcium stearate presented a lower amount of needle-shaped crystals, and some longplatelet or platelet crystal habits. Fig. 8 also depicts for calcium stearate samples an agglomeration of platelet crystals and other prismatic ones. It cannot be ruled out that some of these prismatic crystals might be gypsum crystals, although typical morphologies of calcium sulphate crystals previously reported were not found (such as rosette, leaf-shaped, plate-like, large prismatic crystal forms and so on $[8,20,44])$.

\subsection{Mortars with water-retaining agents}

In spite of the similar weight gain found for all the tested mortars (results not shown), their mechanical performances were significantly different (Fig. 9). Control specimen results (Fig. 9a) showed that when mortars hardened in room conditions, the mixture without any additive presented the largest mechanical strengths. However, when mortars were subjected to more aggressive conditions -such as climatic chamber, outdoor exposure and freezing-thawing cycles-, HPG-samples showed the largest compressive strengths (as an example, Fig. 9b and 9c show the mechanical strengths 
after climatic chamber exposure and freezing-thawing cycles). The increase in air content observed for HPG-mortar helps to explain the lower capillarity coefficient shown by this mixture (air bubbles cut off capillary network). Pore size distributions (Fig. 10) showed that the addition of HPG led to a clear reduction in the percentage of larger pores (from $2 \mu \mathrm{m}$ to $50 \mu \mathrm{m}$ ) (a strong reduction in the peak at $11.3 \mu \mathrm{m}$ can be observed in Fig. 10 when HPG was added: the percentage of total intrusion volume dropped from $13.7 \%$ (control sample) to $3 \%$ (HPG sample) in this pore range). That means that a blockage of the larger pores took place and, at the same time, pore size distribution became more uniform (unimodal) (the percentage of total intrusion volume increased from $46.6 \%$ to $55.5 \%$ in the pore range of $0.5-2 \mu \mathrm{m})$. The densities in fresh state of the mortars, as well as in hardened state, were lower for HPG samples than for the control mortar (fresh mortars: 1869.6 g.L $\mathrm{L}^{-1}$ for HPG-sample and 1942.4 g.L $\mathrm{L}^{-1}$ for control sample. Hardened mortars: 1580 g.L $\mathrm{L}^{-1}$ for HPG sample and 1670 g.L $\mathrm{L}^{-1}$ for control sample). The differences can be due to the air content as well as to the larger amount of mixing water (a water/binder ratio of 1.32 of HPG mortar compared to 1.20 for control mortar). Although HPG mortar turned out to be less dense than control mortar, the growth of the calcite matrix gave rise to a decrease in larger pores when the mortar hardened, as can be proved by the aforementioned percentages of volume of intruded mercury. Both the lower capillarity coefficient, which involves a water intake reduction, and the absence of large pores may be reported as the main factors improving the mechanical behaviour of exposed HPG-samples, and hence their durability. Particularly air voids introduced into the mass of the mortar could also play an important role in liberating the pressures generated during freezing processes, thus increasing the HPG-samples' durability, as Fig. 11 shows [45]. 
HPMC mortar showed a less pronounced reduction in the percentage of large pores between 50 and $2 \mu \mathrm{m}$ than HPG mortar. The percentage of total intrusion volume was $11.6 \%$ for HPMC (whereas $13.7 \%$ was determined for the control sample). By way of explanation for this fact, HPMC required a larger amount of mixing water (1.46 water/binder ratio) than HPG and, in addition, HPMC entrapped a lower amount of air bubbles than HPG (Table 2). The very similar air content would explain why the reference mortars and the HPMC mortars behaved in a similar manner in climatic chamber exposure as well as in freezing-thawing cycles.

As occurred with the water-repelling agents, the exposure of mortars in the $\mathrm{SO}_{2}$ chamber gave rise to calcium sulphite hemihydrate formation. The carbonation of specimens was enhanced, as shown in Table 5 by a $\mathrm{Ca}(\mathrm{OH})_{2}$ percentage decrease. Therefore, the strengths were slightly improved along the $\mathrm{SO}_{2}$-exposure cycles (Fig. 9d).

SEM analysis showed rough spherical and long-platelet crystals of calcium sulphite hemihydrate, together with some plate-like crystals (probably of gypsum) (as an example, Fig. 12 shows some images for mortars modified by HPMC addition). Unlike the mortars modified with water repellents, no agglomerates of acicular crystals were observed.

\subsection{Mortars with fibre}

The addition of fibres involved a rise in the amount of required water (see Table 1). A high dosage of fibre dramatically increased the amount of mixing water (1.55 water/binder ratio compared to 1.20 for control mortar). The density of this last mortar 
showed a clear reduction owing to this water/binder ratio (at hardened state, control mortar presented a density value of 1670 g.L $\mathrm{L}^{-1}$, for PP-1 1630 g.L. $\mathrm{L}^{-1}$ was determined, and 1540 g.L $\mathrm{L}^{-1}$ for PP-2). However, the resistance of mortars with fibre in the face of freezing-thawing cycles was considerably better than that of the reference mortar (Fig. 13a and 13b). It must be highlighted that PP-1 specimens suffered some losses of material during the last cycles owing to a crumbling process (Fig. 13c). Nevertheless, their mechanical performance was better than that of the control mortars (Table 6). PP-2 samples also lost some small parts of material and clearly underwent a swelling phenomenon when immersed in water (Fig. 13d). These mortars did not show a good mechanical performance (Table 6). When samples subjected to freezing-thawing cycles were tested, the strength could not be measured in these mortars. When immersed in water, fibre in high dosage (PP-2 samples) created in the mortars a skeleton, like a superstructure, that held stuck the fragments of material, preventing the disintegration of the mortar. However, the mechanical strength of such superstructure was not relevant: when a very slight stress was applied, the mortar offered no resistance.

The compressive strength results after freezing-thawing cycles (Table 6) as well as climatic chamber (Fig. 14a) can be explained taking into account the pore size distributions of the specimens (Fig. 15a). Analyses showed that the addition of fibre in the low dosage (PP-1) generated a more compact material with lower amount of large pores (the percentage of total intrusion volume dropped from $13.7 \%$ (reference mortar) to $8.6 \%$ (PP-1 mortar) in the pore range of $2-50 \mu \mathrm{m}$ : a clear reduction in the peak at ca. $10 \mu \mathrm{m}$ can be observed in Fig. 15a). It should be noticed that in this case the amount of mixing water was quite similar to that of the control mortar: 1.23 water/binder ratio for PP-1 mortar compared with 1.20 for control mortar. However, the high dosage used 
(PP-2) led to an increase in the number of macropores (the percentage of the total volume of intruded mercury rose from $13.7 \%$ to $21.2 \%$, in the pore range of $2-50 \mu \mathrm{m}$ ). This large porosity could be related to the high amount of mixing water that PP-2 mortar required $(29.3 \%$ of mixing water more than the control mortar). This quantity of large pores could be responsible for the strength drop and water absorption and subsequent swelling phenomenon assessed for PP-2 samples. However, PP-1 specimens behaved in a better way owing to: i) the decrease in larger pores; and ii) the reinforcement typically related to the incorporation of fibres to mortars, since fibres have the ability to absorb internal tensions $[46,47]$.

The performance of these specimens in $\mathrm{SO}_{2}$-chamber matched the previous results of other admixtures: calcium sulphite hemihydrate appeared as the main degradation product and the exposure increased the degree of portlandite carbonation (Table 5). As a consequence of the calcite crystallization, pore size distribution changed towards a unimodal distribution (Fig. 15b): the percentage of the total intrusion volume in the pore range that includes the main peak $(0.5-2 \mu \mathrm{m})$ was $35.5 \%$ for the sample exposed to $\mathrm{SO}_{2}$ atmosphere, while $24.8 \%$ was obtained for sample exposed to room conditions. A reduction of the amount of the smallest and largest pores can also be checked: the peaks at $30.2,17.3$ and $0.04 \mu \mathrm{m}$ disappeared. When the reduction of the largest pores was quantified, in the pore range $2-50 \mu \mathrm{m}$ the percentage of the total intrusion volume changed from $21.2 \%$ (sample exposed to indoor conditions) to $12.7 \%$ (sample exposed to $\mathrm{SO}_{2}$-chamber). In the range of the smallest pores $(0.01-0.1 \mu \mathrm{m})$, the percentage decreased from $9 \%$ to $6 \%$ (Fig. 15b) and mechanical strengths were improved (Fig. 14b). Rough spherical crystals of calcium sulphite hemihydrate and plate-like crystals of gypsum were found by means of SEM-EDAX analysis (Fig. 16). 


\subsection{Mortars with viscosity modifier}

With regard to durability, PS mortars suffered less decay than control mortar in all the environments assayed. PS specimens endured two more freezing-thawing cycles than the reference samples (Fig. 17), and they also showed better compressive strengths (Fig. 18a). Also after outdoor exposure as well as climatic chamber cycles PS specimens turned out to be, generally speaking, stronger than control samples, as compressive strength results after weathering cycles show (Fig. 18b).

This behaviour can be explained as a consequence of the pore structure of the modified mortar. However, the mixing water had not a significant role because the water/binder ratio was the same for control mortar and PS mortar (Table 1). Fig. 19a depicts pore size distributions. It can be observed that specimens modified by PS addition showed smaller pores: the percentage of the total intrusion volume in the pore range $2-50 \mu \mathrm{m}$ decreased from $13.7 \%$ to $11.8 \%$ and the peak at ca. $10 \mu \mathrm{m}$ disappeared. The PS addition also caused a lower quantity of main pore population: in the pore range of the main peak $(0.5-2 \mu \mathrm{m})$ the percentage of the total intrusion volume dropped from $46.6 \%$ to $37.7 \%$. As a result of these facts, the capillarity coefficient was reduced (see Table 2: PS specimens presented lower capillarity coefficient than control mortar) and water intake was hindered as the weight changes confirmed (PS specimens absorbed less water amount than the control mortar owing to their lower amount of both large and capillary pores) (Fig. 20). Open porosity also matched these results: $33.08 \%$ was determined for the control mortar, while $28.36 \%$ was measured for the PS specimen. This pore size distribution observed in the hardened material could be related to the previously 
reported effect of the starch in the fresh specimens of lime mortars, because, by increasing the water retention and acting as a plasticizer, it gave rise to a more coherent material [48].

After $\mathrm{SO}_{2}$ exposure, PS sample showed an increase in the main pore diameter (below 1 $\mu \mathrm{m})$ (Fig. 19b), in agreement with previous results reported for the other admixtures, and related to the carbonation process (in the pore range $0.1-1 \mu \mathrm{m}$, the percentage of the total volume of intruded mercury rose from $57.9 \%$ to $65.5 \%$ ) However, it can be observed a slight rise in the mercury intrusion at a pore diameter of $\sim 2.5 \mu \mathrm{m}$ (with a $38.2 \%$ of increase of the volume of the intruded mercury per gram of sample in the pore range $1.5-5 \mu \mathrm{m})$. The appearance of these pores could be attributed to damage caused by the effect of acid deposition and $\mathrm{CaCO}_{3}$ dissolution [27]. It should be noticed that PS samples suffered a strength drop after $\mathrm{SO}_{2}$-chamber exposure (Fig. 18c), which could be attributed to this increase in larger pores.

SEM observations are depicted in Fig. 21. Rough spherical calcium sulphite hemihydrate crystals can be seen. No acicular crystal habit could be observed in PS modified mortars In accordance with pore size distribution results, pores of around 1 $\mu \mathrm{m}$ can be observed widespread through the image, while larger pores (of around $5 \mu \mathrm{m}$ ) appear on the left-top corner of the picture.

\section{Conclusions}

In connection to environments involving hygroscopic transfers and freezing (climatic chamber, freezing-thawing cycles and outdoor exposure), sodium oleate, when used in 
high dosage, has been shown to be the best additive in improving the durability of lime mortar. After being subjected to these ageing programs, mortars with sodium oleate (high dosage) presented the highest compressive strengths. A high dosage of calcium stearate did not perform in such an efficient way: it was effective in climatic chamber, but mortars did not endure all the freezing-thawing cycles. A low water repellent dosage $(0.06 \%$ of the total dry mortar's weight) was clearly useless to increase the mortar's durability in such environments. Among the water-retaining agents, the guar gum derivative improved the durability of the samples compared to the reference mortar. The HPMC turned out to be ineffective in terms of enhancement of durability for lime-based mortars. The behaviour of mortars with polypropylene fibre was clearly dosagedependent: the lower amount of additive led to an improvement of the mechanical properties compared to the reference mortar. Finally, the starch, by producing a more coherent matrix, also enhanced durability and mechanical strength. All these behaviours have been proved to depend directly on the water absorption capacity of the samples, which was related to the pore size distribution: the lower the amount of absorbed water, the better the mechanical performance and the aesthetic evolution. The air content was found to be very important in increasing the lime mortar's durability, because air-voids affect the capillary network and provide a free space where water can expand during the freezing process without damaging the structure. In general, mortars modified with additives that increased the air-content to a much greater extent than the reference mortar offered better mechanical performance and durability when subjected to the above mentioned environments.

The exposure of all the tested mortars to $\mathrm{SO}_{2}$-chamber gave rise to two phenomena: the increase in the carbonation rate and the formation on the mortar's surface of calcium 
sulphite hemihydrate, as the main degradation product, and secondly calcium sulphate dihydrate crystals: conversion of sulphite into sulphate was not favoured owing to the absence of catalyst. The increase in the carbonation rate can be explained by taking into account the high relative humidity of the $\mathrm{SO}_{2}$-chamber, which allows the calcium hydroxide and the gaseous $\mathrm{CO}_{2}$ to dissolve and form calcium carbonate. As a result, mechanical strengths of the mortars suffered, in general, a slight raise in the course of the cycles and pore size distributions of the samples became more unimodal, being centered in $\sim 1 \mu \mathrm{m}$, owing to the formation of calcite.

On the other hand, calcium sulphite hemihydrate was observed in different crystal habits as a function of the admixture. Mortars with water-repelling agents showed acicular crystals of calcium sulphite hemihydrate, typical of mediums with low $\mathrm{pH}$. This is the first time that such a crystal habit has been reported in $\mathrm{SO}_{2}$ deposition on calcareous materials. Acicular shape was the only habit found in sodium oleate samples, while mortars with calcium stearate showed a lower number of needle-shaped crystals and several agglomerations of platelets and prismatic ones, attributable to both sulphite and sulphate crystals. Water-retainers and fibre-modified specimens showed rough spherical crystals of calcium sulphite hemihydrate and plate-like crystals which could be either sulphite or sulphate. In mortars with starch, only rough spherical sulphite crystals were detected.

\section{Acknowledgements}


The authors want to thank CTH Navarra and Fernando Moreno (Calinsa S.A. Navarra) for the material supplied. We are also grateful to Dr. Jon Joseba Echeberria for his help with SEM and to the staff in Laboratorio de Edificación (Universidad de Navarra) for the material support and invaluable help. This work has been funded by the Ministry of Education and Science of Spain (MAT2007-65478) and FUNA (Fundación Universitaria de Navarra).

\section{References}

[1] Conclusions of the symposium "Mortars, Cements and Grouts Used in Conservation of Historic Buildings", Rome, Mater Struct 23 (1990) 235.

[2] J. Lanas, J.I. Alvarez, Masonry repair lime-based mortars: Factors affecting the mechanical behavior, Cem Concr Res 33(2003) 1867-1876.

[3] A. Moropoulou, A. Bakolas, P. Moundoulas, E. Aggelakopoulou, S. Anagnostopoulou, Strength development and lime reaction in mortars for repairing historic masonries, Cem Concr Compos 27 (2005) 289-294.

[4] Y. Sébaïbi, R.M. Dheilly, M. Quéneudec, A study of the viscosity of lime-cement paste: influence of the physico-chemical characteristics of lime, Constr Build Mater 18 (2004) 653-660.

[5] S.F. Marques, R.A. Ribeiro, L.M. Silva, V.M. Ferreira, J.A. Labrincha, Study of rehabilitation mortars: Construction of a knowledge correlation matrix, Cem Concr Res 36 (2006) 1894-1902.

[6] I. Karatasios, V. Kilikoglou, P. Theoulakis, B. Colston, D. Watt, Sulphate resistance of lime-based barium mortars, Cem Concr Compos 30 (2008) 815-821.

[7] M. Stefanidou, I. Papayianni, The role of aggregates on the structure and properties of lime mortars, Cem Concr Compos 27 (2005) 914-919.

[8] J. Lanas, R. Sirera, J.I. Alvarez, Study of the mechanical behavior of masonry repair lime-based mortars cured and exposed under different conditions, Cem Concr Res 36 (5) (2006) 961-970.

[9] C. Gosselin, V. Verges-Belmin, A. Roger, G. Martinet, Natural cement and monumental restoration, Mater Struct 42 (6) (2009) 749-763.

[10] T. Cerulli, C. Pistolesi, C. Maltese, D. Salvioni, Durability of traditional plasters with respect to blast furnace slag-based plaster, Cem Concr Res 33 (2003) 1375-1383. 
[11] I. Papayianni, M. Stefanidou, Durability aspects of ancient mortars of the archeological site of Olynthos, J Cult Herit 8 (2007) 193-196.

[12] M. Ghrici, S. Kenai, M. Said-Mansour, Mechanical properties and durability of mortar and concrete containing natural puzzolana and limestone blended cements, Cem Concr Compos 29 (2007) 542-549.

[13] M. Lanzón-Torres, P.A. García-Ruiz, Lightweight puzzolanic materials used in mortars: Evaluation of their influence on density, mechanical strength and water absorption, Cem Concr Compos 31 (2009) 114-119.

[14] M. Arandigoyen, J.L. Pérez-Bernal, M.A. Bello-López, J.I. Alvarez, Lime-pastes with different kneading water: Pore structure and capillary porosity, Appl Surf Sci 252 (2005) 1449-1459.

[15] P. Faria, F. Henriques, V. Rato, Comparative evaluation of lime mortars for architectural conservation, J Cult Herit 9 (2008) 338-346.

[16] J. Lanas, J.L. Perez Bernal, M.A. Bello, J.I. Alvarez, Mechanical properties of masonry repair dolomitic lime-based mortars, Cem Concr Res 36 (5) (2006) 951-960.

[17] S. Pavía, S. Caro, An investigation of Roman mortar technology through the petrographic analysis of archaeological material, Constr Build Mater 22 (2008) 18071811.

[18] M.P. Seabra, H. Paiva, J.A. Labrincha, V.M. Ferreira, Admixtures effect on fresh state properties of aerial lime based mortars, Constr Build Mater 23 (2009) 1147-1153.

[19] C. Sabbioni, G. Zappia, C. Riontino, M.T. Blanco-Varela, J. Aguilera, F. Puertas, K. Van Balen, E.E. Toumbakari, Atmospheric deterioration of ancient and modern hydraulic mortars, Atmos Environ 35 (2001) 539-548.

[20] G. Cultrone, A. Arizzi, E. Sebastián, C. Rodríguez-Navarro, Sulfation of calcitic and dolomitic lime mortars in the presence of diesel particulate matter, Environ Geol 56 (2008) 741-752.

[21] G. Zappia, C. Sabbioni, M.G. Pauri, G. Gobbi, Mortar damage due to airborne sulfur compounds in a simulation chamber, Mater Struct 27 (1994) 469-473.

[22] J.L. Pérez Bernal, M.A. Bello, Dióxido de azufre. Química atmosférica y destrucción del patrimonio, Fundación El Monte, Sevilla, 2004.

[23] P. Elfving, I. Panas, O. Lindqvist, Model study of the first steps in the deterioration of calcareous stone I. Initial surface sulphite formation on calcite, Appl Surf Sci 74 (1994) 91-98.

[24] P. Elfving, I. Panas, O. Lindqvist, Model study of the first steps in the deterioration of calcareous stone II. Sulphate formation on calcite, Appl Surf Sci 78 (1994) 83-92. 
[25] J. Lanas, R. Sirera, J.I. Alvarez, Compositional changes in lime-based mortars exposed to different environments, Thermochim Acta 429 (2005) 219-226.

[26] S. Martínez-Ramírez, F. Puertas, M.T. Blanco-Varela, G.E. Thompson, Studies on degradation of lime mortars in atmospheric simulation Chambers, Cem Concr Res 27 (5) (1997) 777-784.

[27] S. Martínez-Ramírez, F. Puertas, M.T. Blanco-Varela, G.E. Thompson, P. Almendros, Behaviour of repair lime mortars by wet deposition process, Cem Concr Res 28 (1998) 221-229.

[28] K. Beck, M. Al-Mukhtar, Formulation and characterization of an appropriate limebased mortar for use with a porous limestone, Environ Geol 56 (2008) 715-727.

[29] A. Izaguirre, J. Lanas, J.I. Álvarez, Effect of water-repellent admixtures on the behaviour of aerial lime-based mortars, Cem Concr Res 39 (2009) 1095-1104.

[30] M.J. Mosquera, B. Silva, B. Prieto, E. Ruiz-Herrera, Addition of cement to limebased mortars: Effect on pore structure and vapor transport, Cem Concr Res 36 (2006) $1635-1642$.

[31] UNE-EN 459-1, Building lime. Part 1. Definition, specification and conformity criteria (2001).

[32] UNE-EN 1015-11, Methods of test for mortar for masonry. Part 11: Determination of flexural and compressive strength of hardened mortar (2000).

[33] UNE-EN 1015-7, Methods of test for mortar for masonry. Part 7: Determination of air content of fresh mortar (1999).

[34] UNE-EN 1015-18, Methods of test for mortar for masonry. Part 18: Determination of water absorption coefficient due to capillary action of hardened mortar (2003).

[35] UNE-EN 1015-19, Methods of test for mortar for masonry. Part 19: Determination of water vapour permeability of hardened rendering and plastering mortars (1999).

[36] H. Böke, S. Akkurt, S. Özdemir, E.H. Göktürk, E.N. Caner-Saltik, Quantification of $\mathrm{CaCO}_{3}-\mathrm{CaSO}_{3} \cdot 0.5 \mathrm{H}_{2} \mathrm{O}-\mathrm{CaSO}_{4} \cdot 2 \mathrm{H}_{2} \mathrm{O}$ mixtures by FTIR analysis and its $\mathrm{ANN}$ model, Mater Lett 58 (2004) 723-726.

[37] R.M. Dheilly, J. Tudo, Y. Sebaibi, M. Quéneudec, Influence of storage conditions on the carbonation of powdered $\mathrm{Ca}(\mathrm{OH})_{2}$, Constr Build Mater 16 (2002) 155-161.

[38] M. Arandigoyen, B. Bicer-Simsir, J.I. Alvarez, D.A. Lange, Variation of microstructure with carbonation in lime and blended pastes, Appl Surf Sci 252 (2006) $7652-7571$.

[39] F. Collet, M. Bart, L. Serres, J. Miriel, Porous structure and water vapour sorption of hemp-based materials, Constr Build Mater 22 (2008) 1271-1280. 
[40] J. Lanas, J.L. Perez-Bernal, M.A. Bello, J.I. Alvarez Galindo, Mechanical properties of natural hydraulic lime-based mortars, Cem Concr Res 34 (2004) 21912201.

[41] P. C. Chen, C.Y. Tai, S.M. Shih, Control of crystal habit and particle morphology of calcium sulfite hemihydrate crystals, J Cryst Growth 123 (1997) 277-286.

[42] H. Böke, E.H. Göktürk, E.N. Caner-Saltik, S. Demirci, Effect of airborne particle on $\mathrm{SO}_{2}$-calcite reaction, Appl Surf Sci 140 (1999) 70-82.

[43] H. Böke, E.H. Göktürk, E.N. Caner-Saltik, Effect of some surfactants on $\mathrm{SO}_{2}$ marble reaction, Mater Lett 57 (2002) 935-939.

[44] B.J. Buck, J.G.Van Hoesen, Snowball morphology and SEM analysis of pedogenic gypsum, southern New Mexico, U.S.A., J Arid Environ 51 (2002) 469-487.

[45] S. Chatterji, Freezing of air-entrained cement-based materials and specific actions of air-entraining agents, Cem Concr Compos 25 (2003) 759-765.

[46] A. García-Santos, J.M. Rincón, M. Romero, R. Talero, Characterization of a polypropylene fibered cement composites using ESEM, FESEM and mechanical testing, Constr Build Mater 19 (2005) 396-403.

[47] R. D. Tolêdo-Filho, M.A. Sanjuán, Effect of low modulus sisal and polypropylene fibre on the free and restrained shrinkage of mortars at early age, Cem Concr Res 29 (1999) 1597-1604.

[48] A. Izaguirre, J. Lanas, J.I. Álvarez, Behaviour of a starch as a viscosity modifier admixture for aerial lime-based mortars, Carbohydr Polym (2009), doi:

10.1016/j.carbpol.2009.11.010. 


\begin{tabular}{c|c|c|c|c} 
Sample & Additive & Water & $\begin{array}{c}\text { Additive/lime ratio } \\
\mathbf{( \% )}\end{array}$ & $\begin{array}{c}\text { Mixing water/lime } \\
\text { ratio }\end{array}$ \\
\hline REF & - & 410 & 0 & 1.20 \\
\hline SO-1 & SO (0.96 g) & 400 & 0.3 & 1.17 \\
\hline SO-2 & SO (8.16 g) & 440 & 2.4 & 1.29 \\
\hline CS-1 & CS (0.98 g) & 420 & 0.3 & 1.23 \\
\hline CS-2 & CS (8.16 g) & 440 & 2.4 & 1.29 \\
\hline HPMC & HPMC (0.98 g) & 500 & 0.3 & 1.46 \\
\hline HPG & HPG (0.98 g) & 450 & 0.3 & 1.32 \\
\hline PP-1 & PP $(0.98 \mathrm{~g})$ & 420 & 0.3 & 1.23 \\
\hline PP-2 & PP $(8.16 \mathrm{~g})$ & 530 & 2.4 & 1.55 \\
\hline PS & PS $(8.16 \mathrm{~g})$ & 410 & 2.4 & 1.20
\end{tabular}

Table 1. Amounts of additive and water in the studied mortars.

\begin{tabular}{|c|c|c|c|c|c|c|c|c|c|c|}
\hline \multirow{2}{*}{ Properties } & \multicolumn{10}{|c|}{ Samples } \\
\hline & REF & SO-1 & SO-2 & CS-1 & CS-2 & HPMC & HPG & PP-1 & PP-2 & PS \\
\hline Air content (\%) & 2.8 & 4.2 & 4.2 & 3.7 & 3.4 & 3.4 & 5.0 & 2.8 & 3.6 & 3.3 \\
\hline $\begin{array}{l}\text { Capillarity coefficient } \\
\left(\mathrm{kg} / \mathrm{m}^{2} \cdot \mathrm{min}^{1 / 2}\right)\end{array}$ & 2.36 & 0.58 & 0.06 & 1.59 & 1.40 & 2.73 & 1.96 & 2.31 & 2.40 & 1.85 \\
\hline Permeability coefficient & 16.6 & 15.3 & 14.9 & 20.8 & 15.7 & 12.6 & 15.0 & 21.1 & 13.5 & 19.1 \\
\hline
\end{tabular}

Table 2. Results of air content, capillarity coefficient and permeability coefficient for the tested mortars.

\begin{tabular}{c|cccccc} 
Cycle duration & Steps & Temperature $\left({ }^{\circ} \mathbf{C}\right)$ & RH (\%) & Rain & UV Light & Time (h) \\
\hline \multirow{6}{*}{48 hours } & Step 1 & 35 & 30 & no & No & 12 \\
& Step 2 & 45 & 20 & no & Yes & 12 \\
& Step 3 & 12 & 95 & yes & No & 1 \\
& Step 4 & 12 & 95 & no & No & 4.5 \\
& Step 5 & 12 & 95 & yes & No & 1 \\
& Step 6 & 12 & 95 & no & No & 4.5 \\
& Step 7 & 12 & 95 & yes & No & 1 \\
& Step 8 & -5 & 0 & no & No & 12
\end{tabular}

Table 3. Characteristics of the cycles in the climatic chamber. 


\begin{tabular}{c|ccccc} 
Time of exposure (days) & \multicolumn{5}{|c}{ Degree of alteration } \\
\hline & REF & SO-1 & SO-2 & CS-1 & CS-2 \\
$\mathbf{2}$ & 0 & 0 & 0 & $0-1$ & 0 \\
$\mathbf{1 4}$ & 4 & $0-1$ & 0 & 2 & 0 \\
$\mathbf{2 1}$ & 5 & $2-3$ & 0 & 5 & 2 \\
$\mathbf{2 8}$ & $(-)$ & 5 & 0 & $(-)$ & 5 \\
& $(-)$ & $(-)$ & 0 & $(-)$ & $(-)$
\end{tabular}

(-) Not determined because samples showed a whole decay in the previous evaluation

Equivalences of the alteration degrees:

0 : Without alteration.

1: Slightly altered, some small (thin and short) cracks on the surface of the specimens.

2: Altered, several cracks (like spider's web) and deeper.

3: Very altered, several deep cracks and swelling of the specimen.

4: High degree of alteration, large and deep cracks, large swelling of the specimen including a partial weight loss.

5: Completely altered, the specimen is practically destroyed, only little pieces of it are kept.

Table 4. Qualitative evaluation of the mortars after freezing-thawing cycles.

\begin{tabular}{c|c|c}
\multirow{2}{*}{} & \multicolumn{2}{|c}{$\mathbf{C a}(\mathbf{O H})_{\mathbf{2}} \mathbf{( \% )}$} \\
\cline { 2 - 3 } Control group & After $\mathrm{SO}_{2}$ exposure \\
\hline REF & 1.2 & 0.6 \\
\hline SO-1 & 2.4 & 0.3 \\
\hline SO-2 & 1.7 & 0.5 \\
\hline CS-1 & 0.9 & 0.5 \\
\hline CS-2 & 3.6 & 0.4 \\
\hline HPMC & 1.3 & 0.5 \\
\hline HPG & 1.8 & 0.5 \\
\hline PP-1 & 2.0 & 0.3 \\
\hline PP-2 & 1.7 & 1.0 \\
\hline PS & 0.9 & 0.4
\end{tabular}

Table 5. Percentage of $\mathrm{Ca}(\mathrm{OH})_{2}$ in samples exposed to $\mathrm{SO}_{2}$ and in control specimens determined by $\mathrm{TG}$ analysis.

\begin{tabular}{c|ccc} 
Time of exposure (days) & \multicolumn{4}{|c}{ Compressive strength $\left(\mathbf{N} / \mathbf{m m}^{\mathbf{2}}\right)$} \\
\hline \multirow{7}{*}{} & REF & PP-1 & PP-2 \\
$\mathbf{1 4}$ & 1,19 & 4,20 & Squashed \\
& $(-)$ & 1,87 & Squashed
\end{tabular}

(-) Not determined because samples had been previously destroyed.

Table 6. Compressive strengths of polypropylene fibre-modified mortars after freezingthawing cycles. 


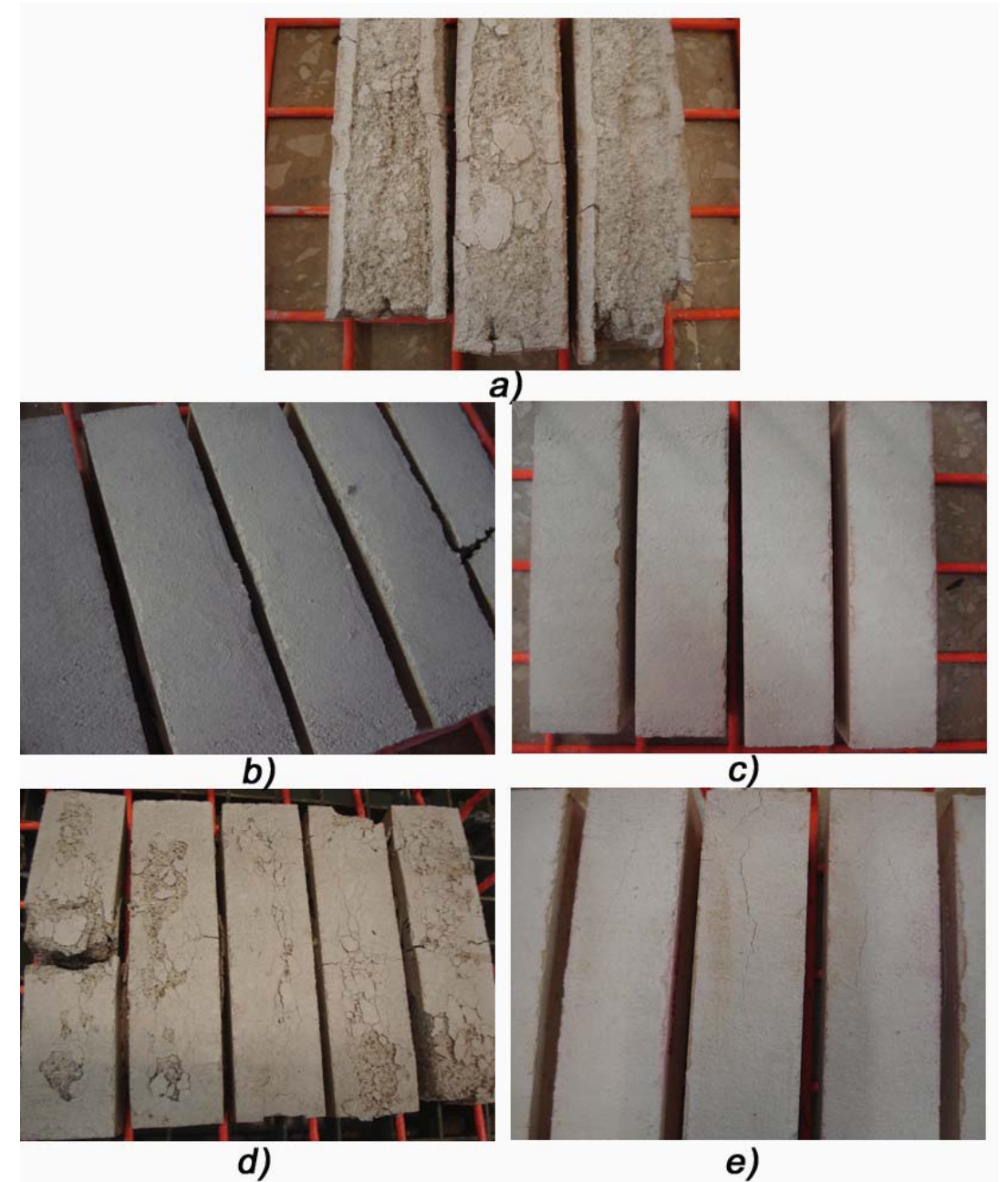

Figure 1. The studied mortars after freezing-thawing cycles: a) REF specimens after 6 cycles, clearly destroyed; b) SO-1 samples after 6 cycles, mainly intact; c) SO-2 samples after 14 cycles, without any sign of deterioration; d) CS-1 mortars after 6 cycles, destroyed; e) CS-2 specimens after 6 cycles, clearly improved with respect to the reference. 

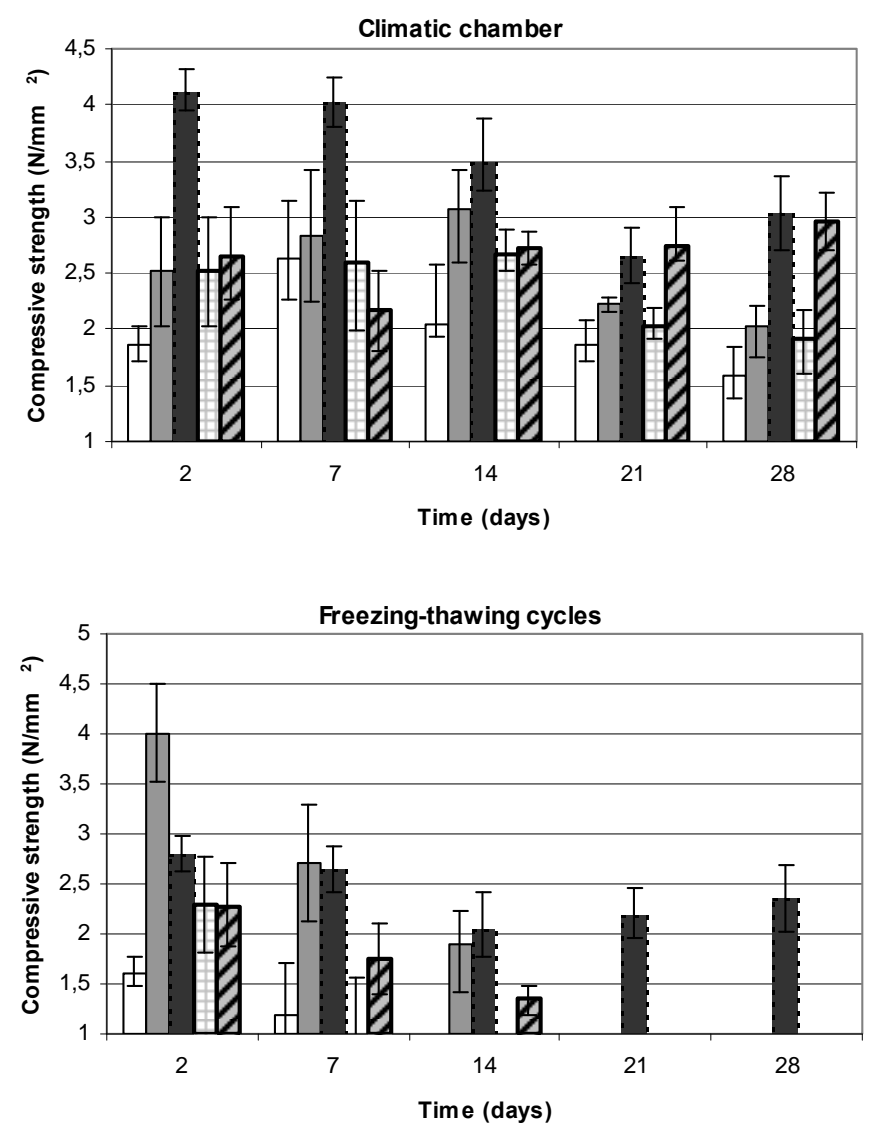

a)

b)

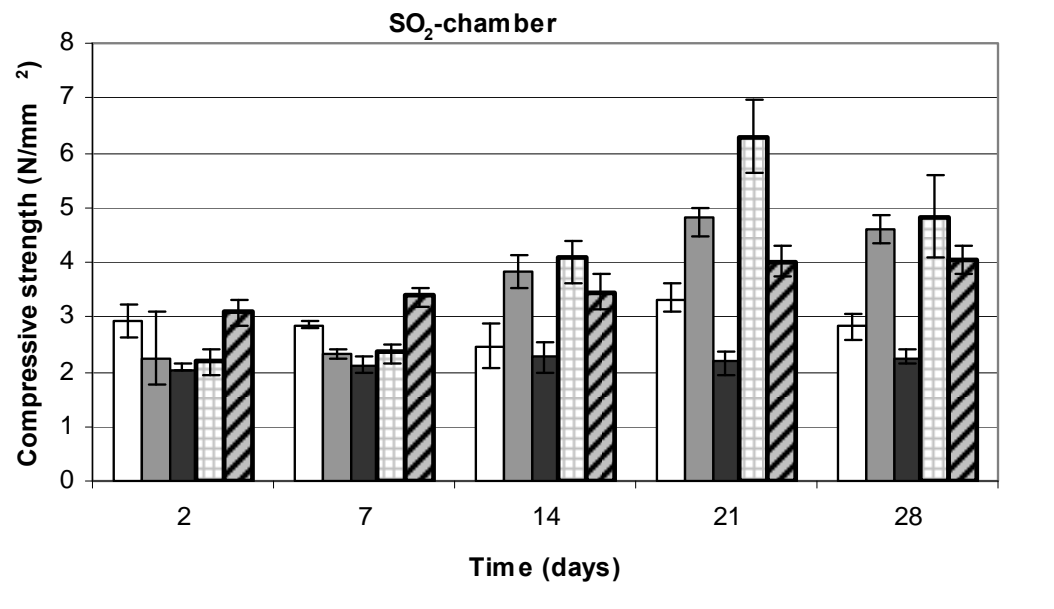

$\square$ REF

$\square$ SO-1

$\square \mathrm{SO}-2$

$\square$ CS-1

चCS-2

c)

Figure 2. Mechanical strength results of mortars modified with water-repelling agents (sodium oleate, $\mathrm{SO}$, and calcium stearate, $\mathrm{CS}$ ), as well as the control material, after being subjected to different exposures. 

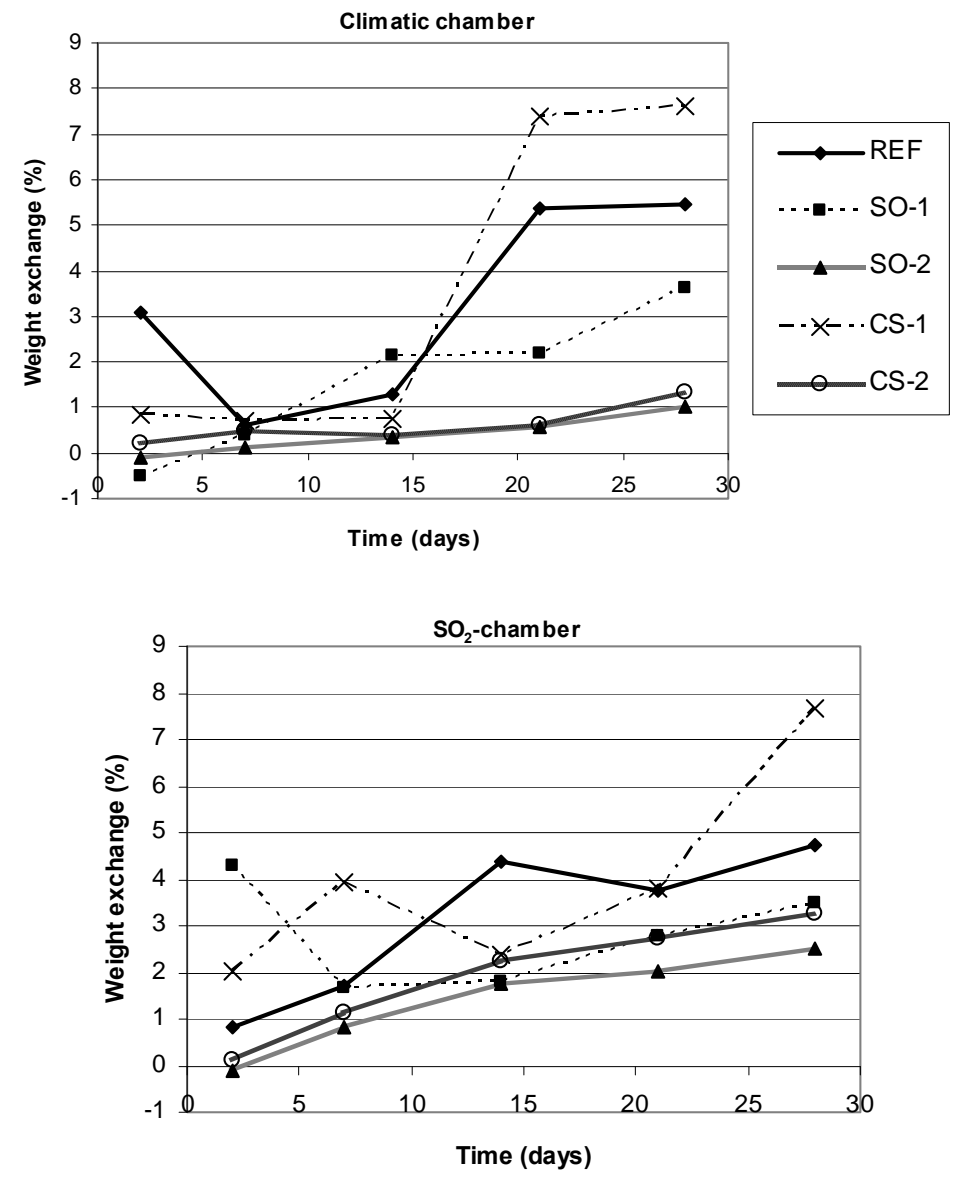

Figure 3. Weight change of reference samples and mortars modified with waterrepelling agents during climatic chamber and $\mathrm{SO}_{2}$-chamber exposures. 


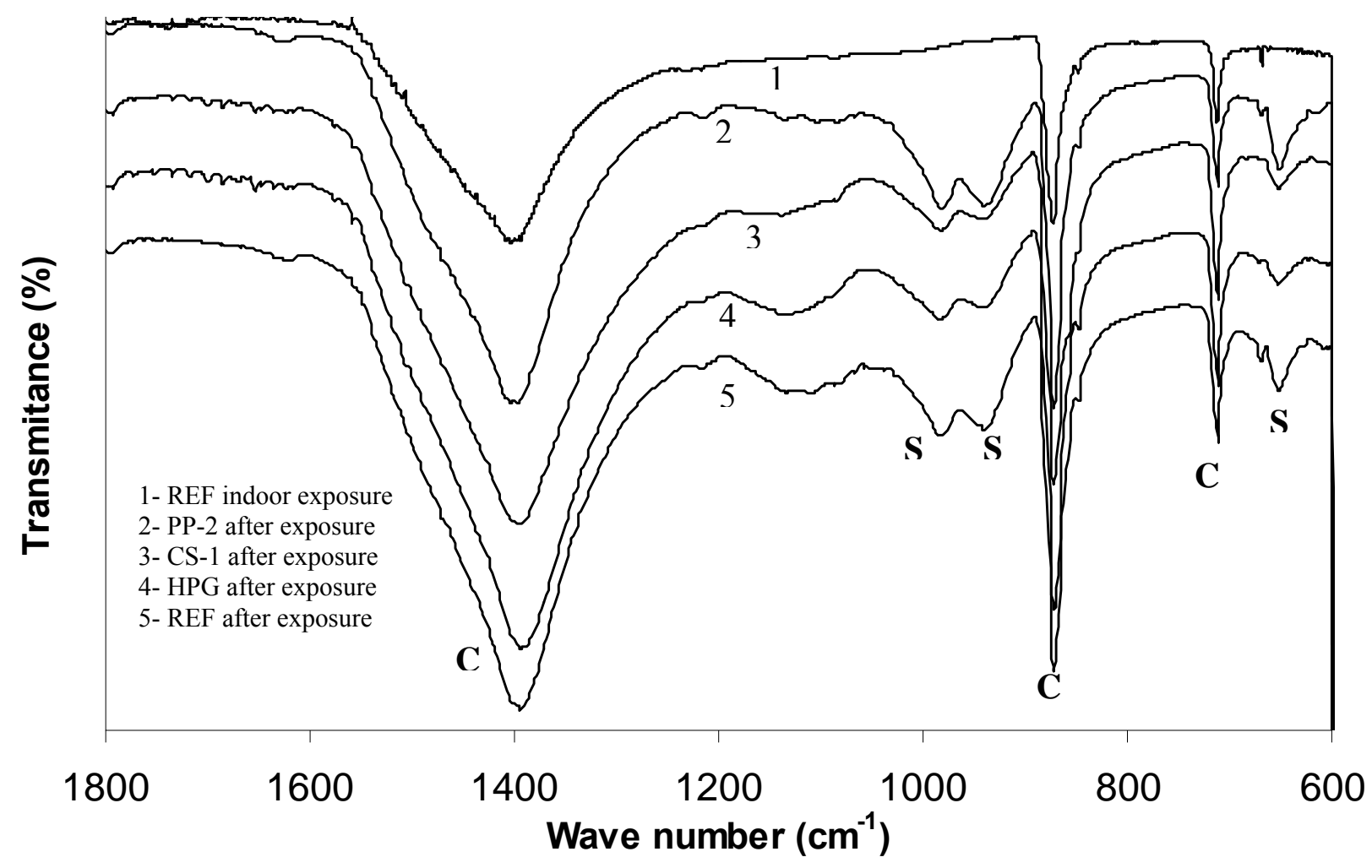

Figure 4. IR spectra of several samples after being exposed to $\mathrm{SO}_{2}$ cycles compared with the reference mortar without exposure, where: C: calcite; S: calcium sulphite hemihydrate. 


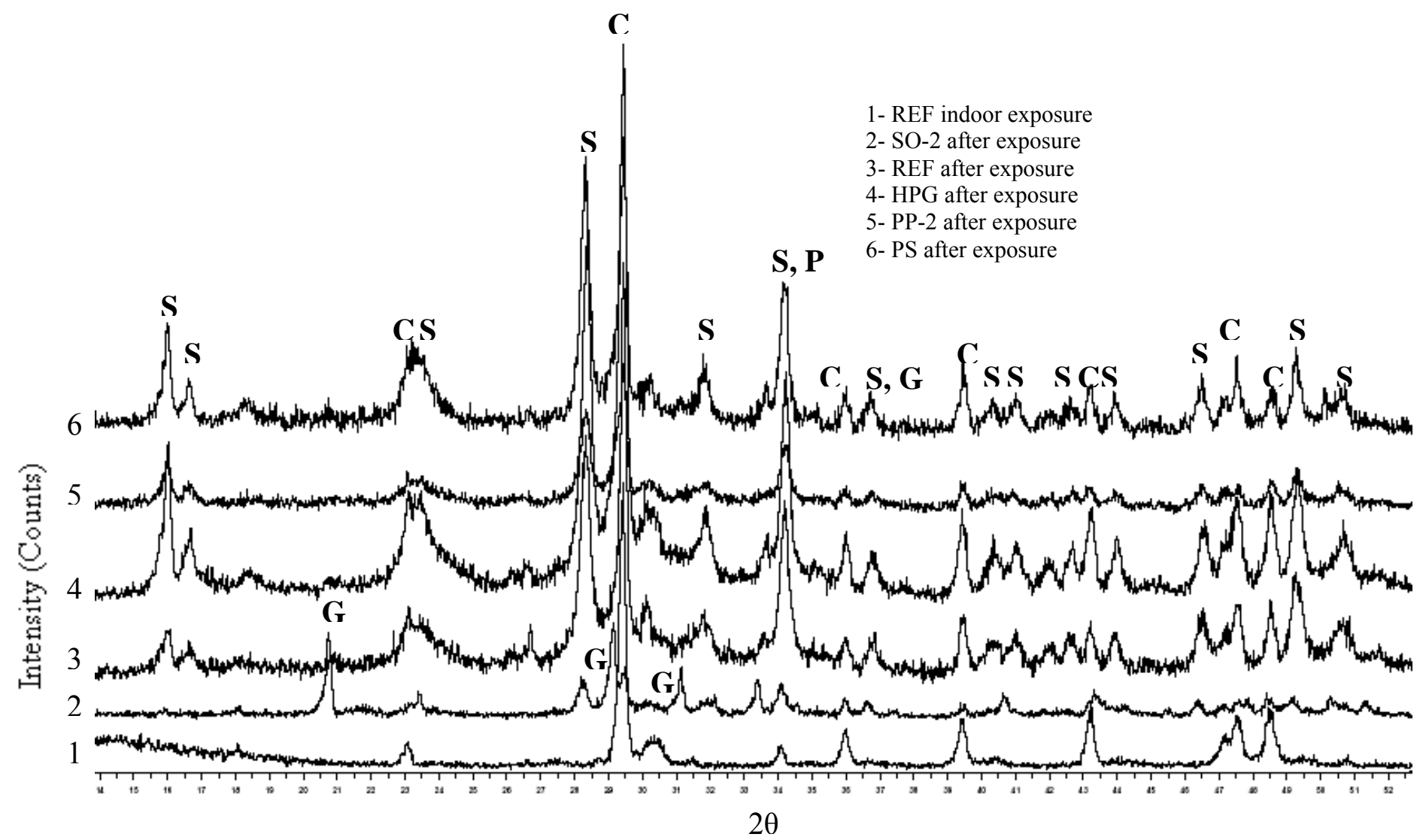

Figure 5. XRD pattern of several studied mortars after being subjected to $\mathrm{SO}_{2}$-chamber, where: C: calcite (ICDD 05-0586); P: portlandite (ICDD 44-1481); G: gypsum (ICDD 33-0311); S: calcium sulphite hemydrate (ICDD 39-0725). 


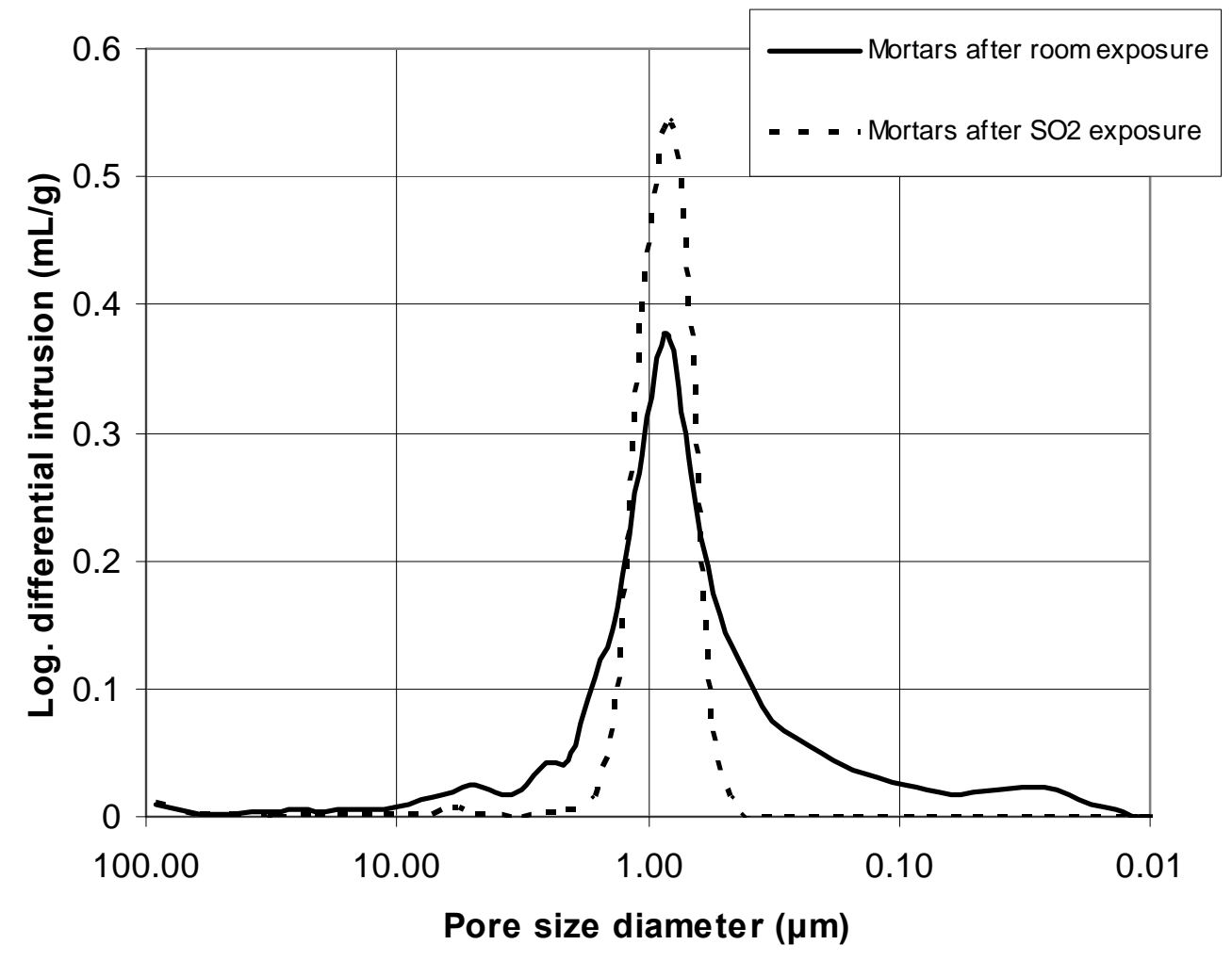

Figure 6. Pore size distribution of mortars with sodium oleate in high dosage after being exposed to room conditions and to $\mathrm{SO}_{2}$ cycles. 


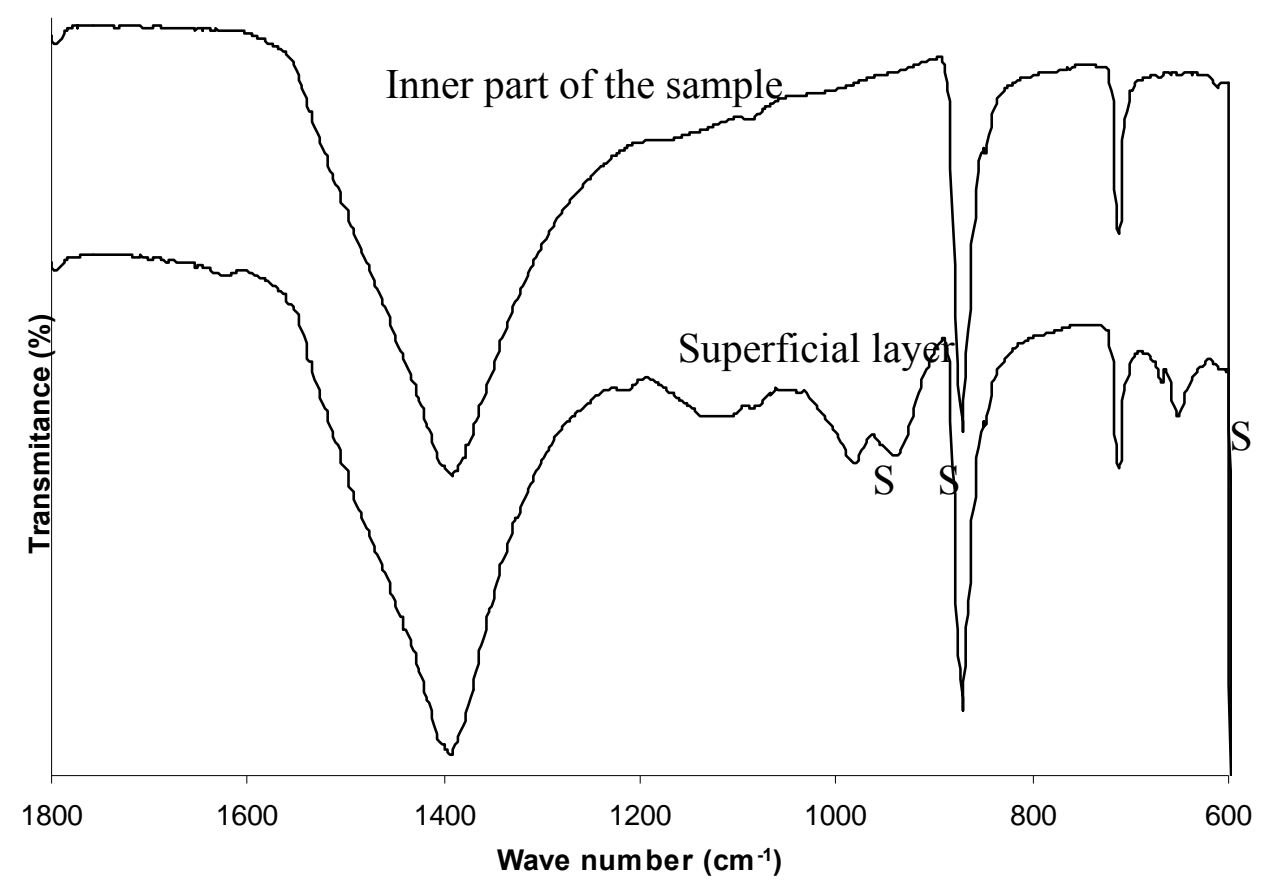

a)

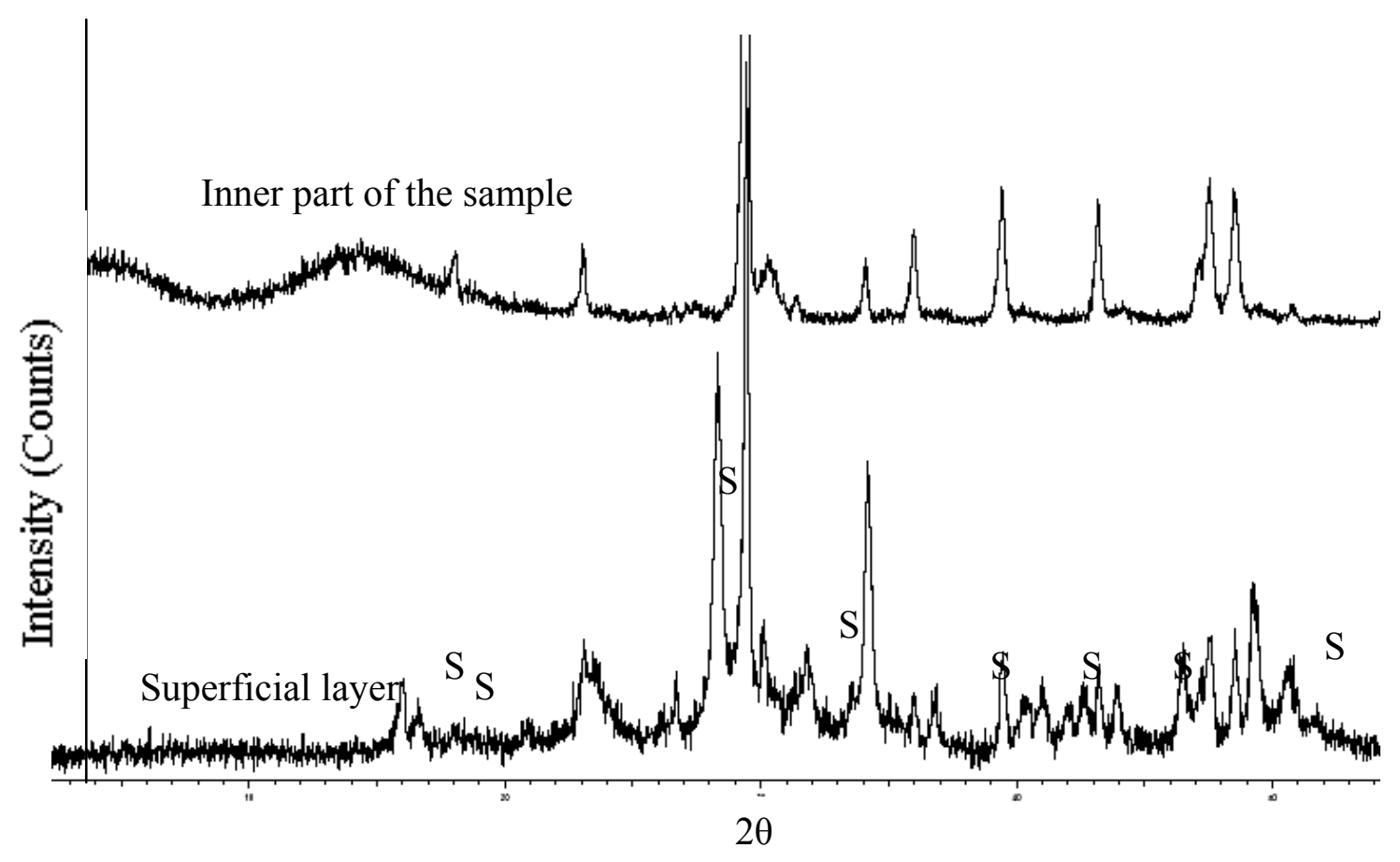

b)

Figure 7. Comparison between the inner part and the superficial layer of a reference sample after exposure to $\mathrm{SO}_{2}$-chamber during 28 days: a) IR spectrum, showing the characteristic absorption bands of calcium sulphite hemihydrate (S) only in the superficial layer; b) XRD patterns, showing the main peaks related to calcium sulphite hemihydrate (S) (ICDD 39-0725) only in the analysis of the superficial layer. 

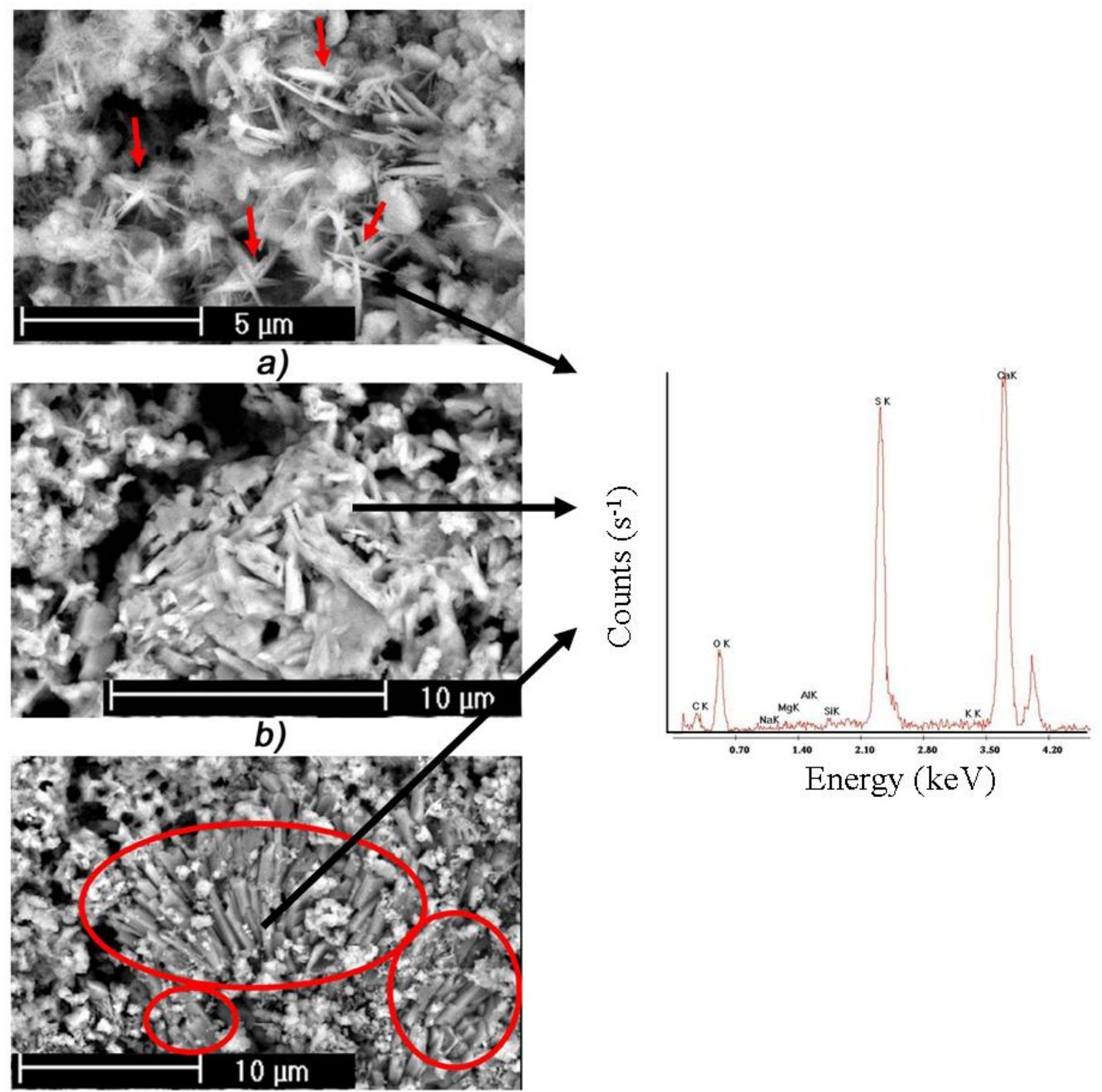

c)

Figure 8. SEM images of the surface of mortars modified with water-repelling agents after exposure to $\mathrm{SO}_{2}$-chamber: a) agglomerates of acicular calcium sulphite hemihydrate in samples with high dosage of sodium oleate; b) and c) mortars modified by calcium stearate at low dosage, showing a low amount of needle-shaped crystals, and some long-platelet or platelet crystal habits. In b) an agglomeration of long-platelet crystals, in the centre of the picture, gives rise to a large structure. 

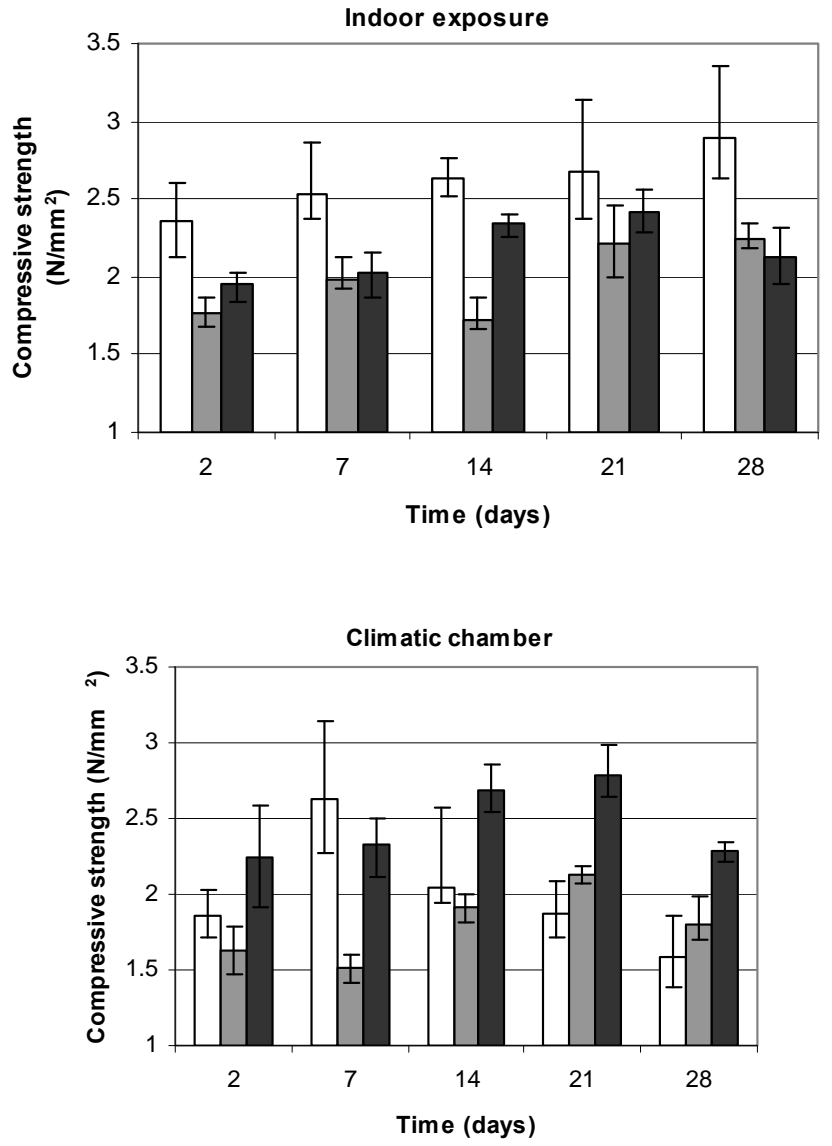

a)

b) 

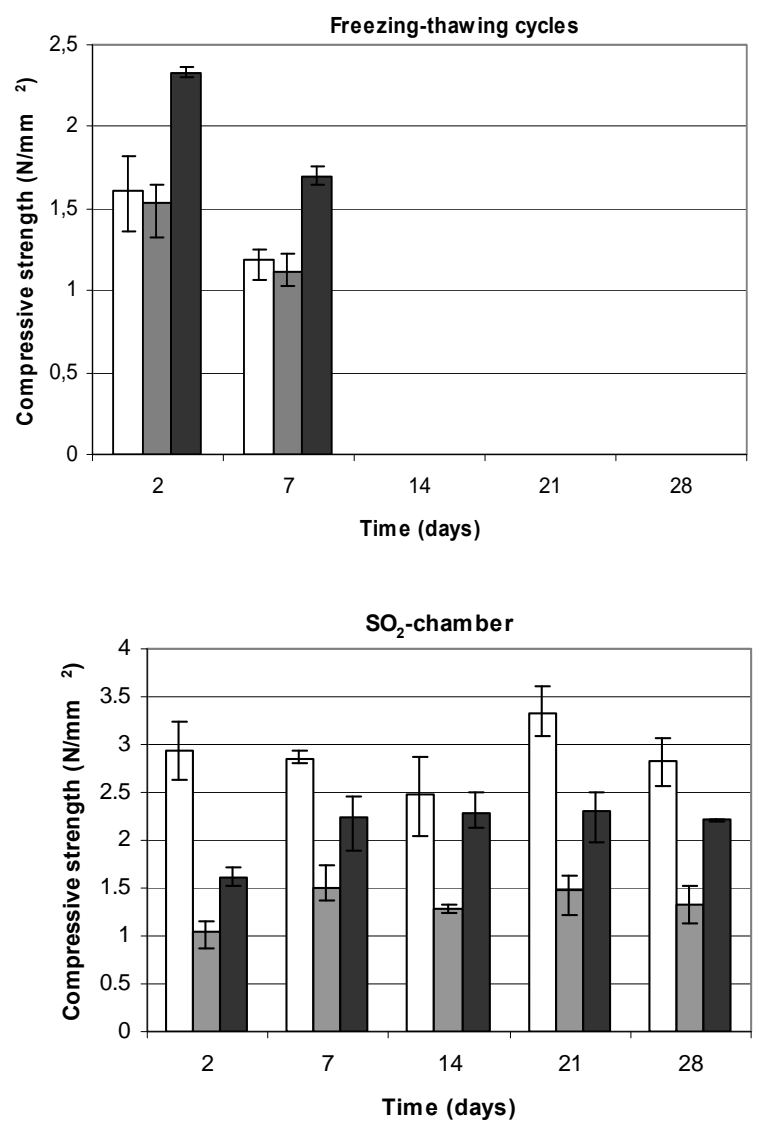

c)

d)

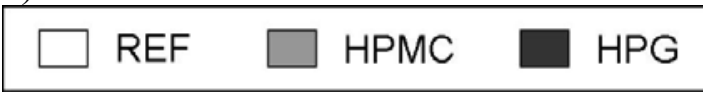

Figure 9. Compressive strenghts of mortars modified with water-retaining agents and the control material alter being subjected to several exposures. 


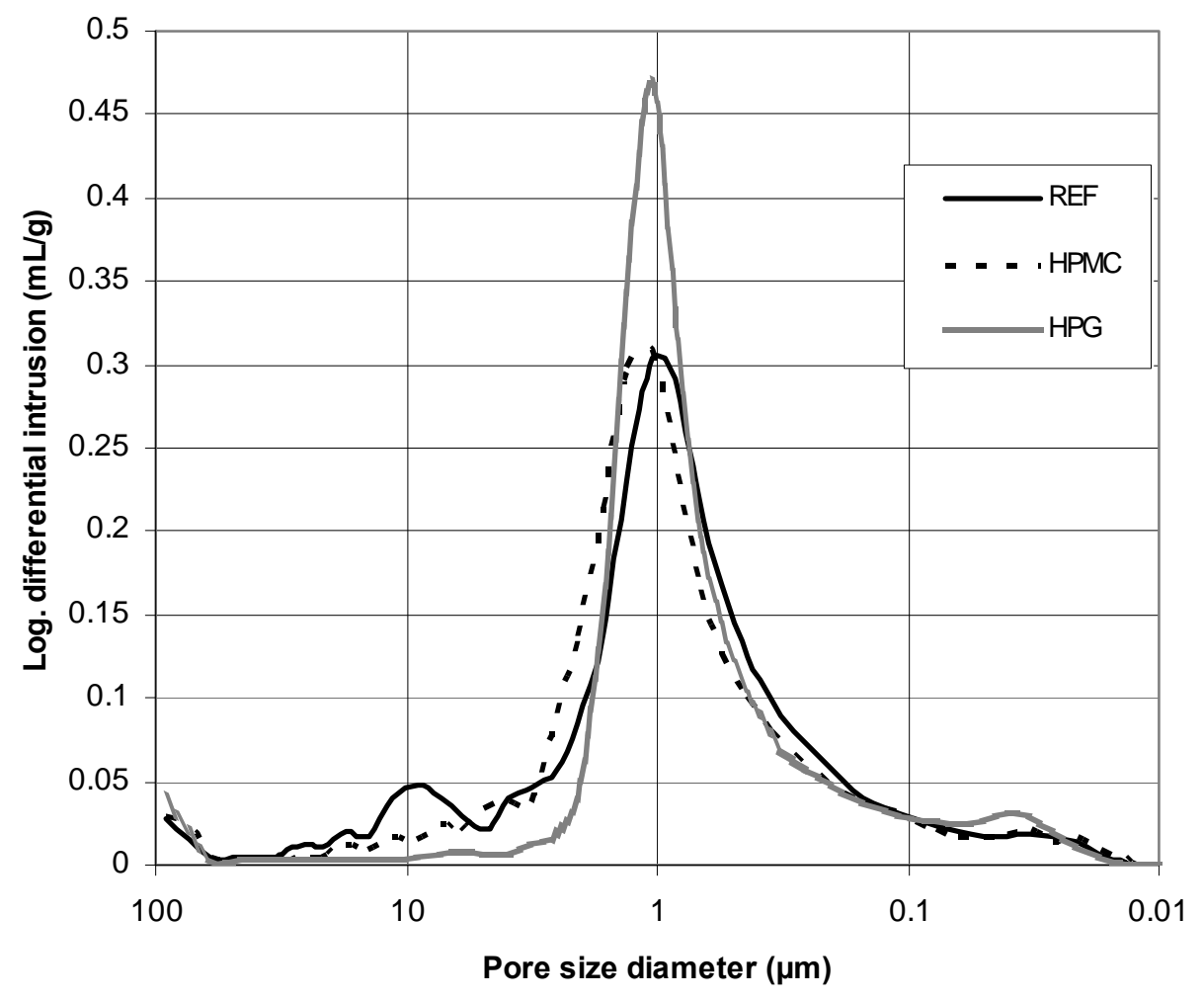

Figure 10. Pore size distribution of the mortars with water retainers and the control mixture.

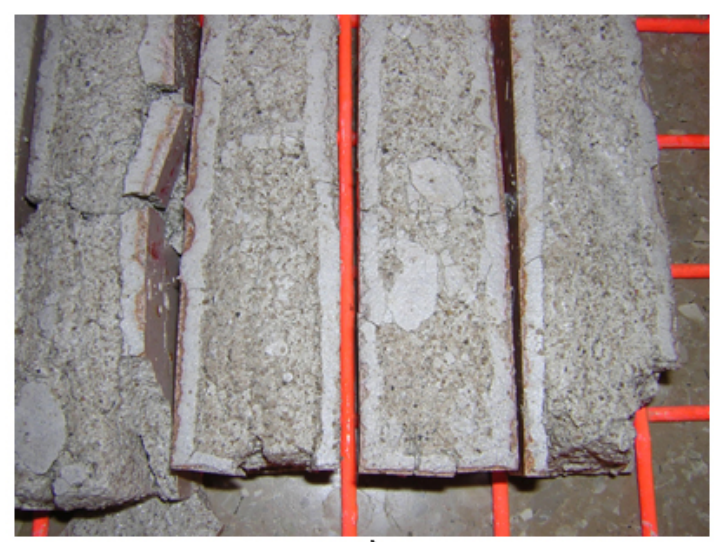

a)

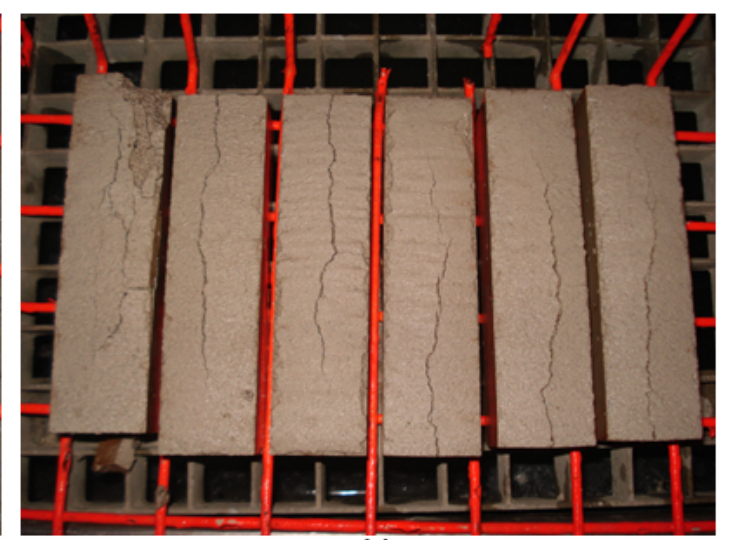

b)

Figure 11. a) REF samples after 6 freezing-thawing cycles, with a high degree of decay, losses of material and deep cracks (degree 5 of decay); b) HPG mortars after 6 freezingthawing cycles, with some longitudinal cracks, but clearly less affected than reference specimens (degree 3-4). 


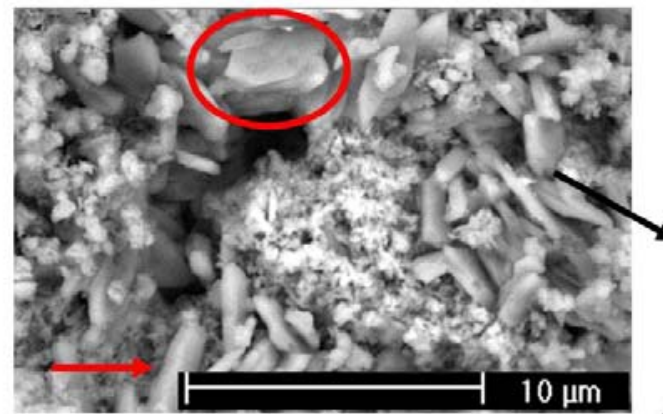

a)

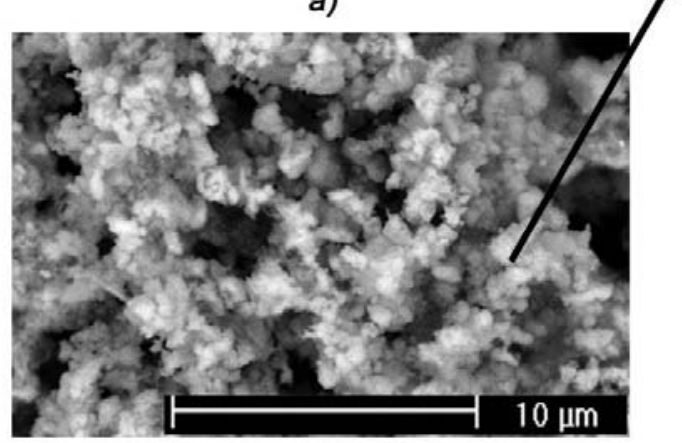

b)

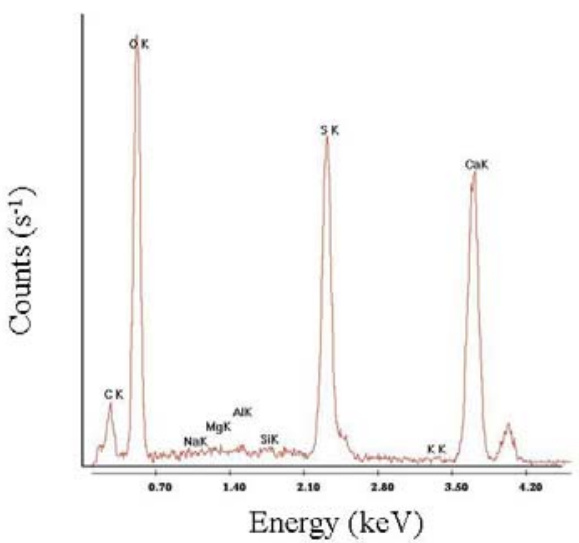

Figure 12. SEM images of HPMC mortars after exposure to $\mathrm{SO}_{2}$-chamber: a) rough spherical crystals of calcium sulphite hemihydrate (in the middle of the picture), longplatelet crystals of the same compound (fixed with an arrow) and some plate-like crystals -probably of gypsum-(surrounded with a circle); b) rough spherical crystals of calcium sulphite hemihydrate. 


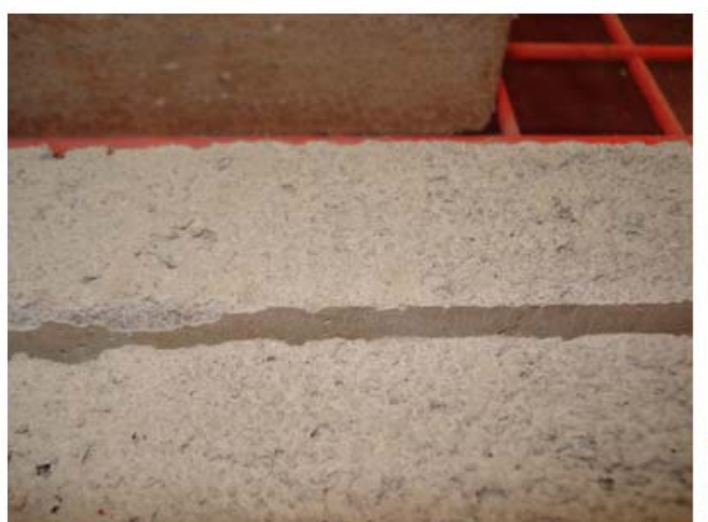

a)

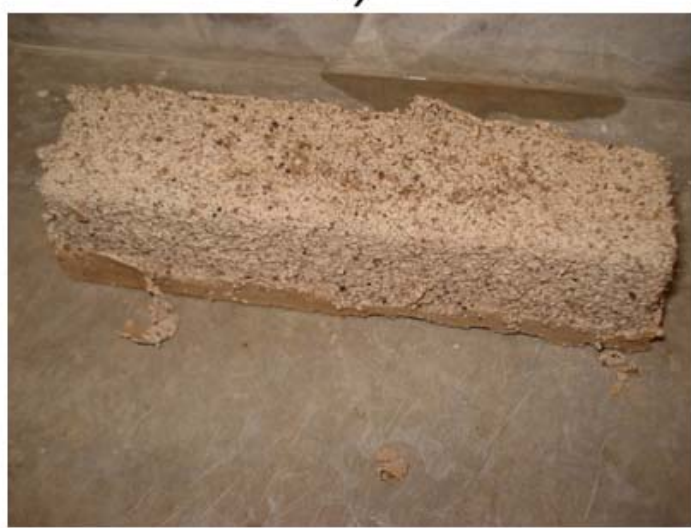

c)

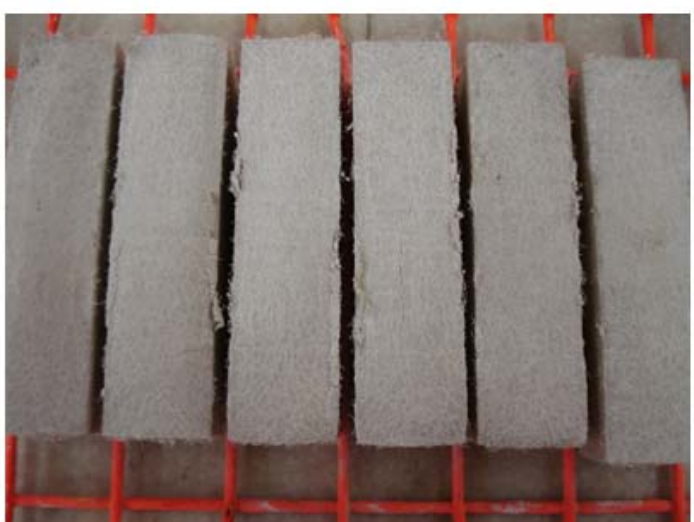

b)

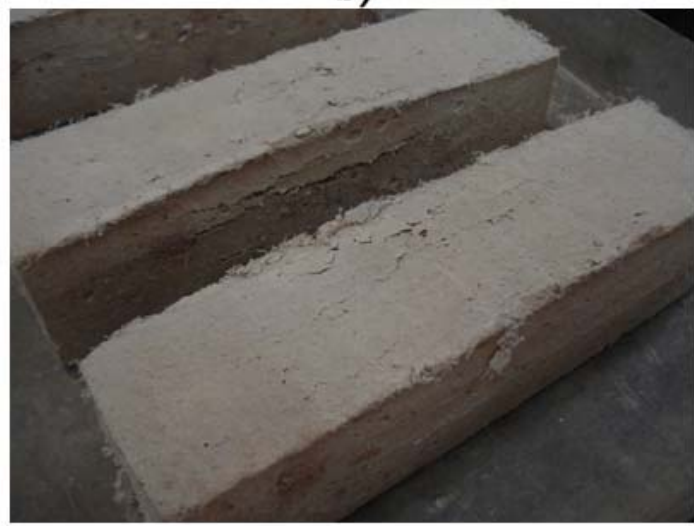

d)

Figure 13. Polypropylene fibre-modified mortars during freezing-thawing cycles: a) PP-1 samples after 6 freezing-thawing cycles (degree 1 of decay), clearly less affected than the reference material (see Fig. 11 a); b) PP-2 mortars after 6 cycles (degree 1), also showing better resistance than the control mortar; c) PP-1 samples after 14 cycles, with considerable crust losses (degree 4-5); d) PP-2 mortars after 14 cycles, presenting great swelling and longitudinal cracks (degree 4). 

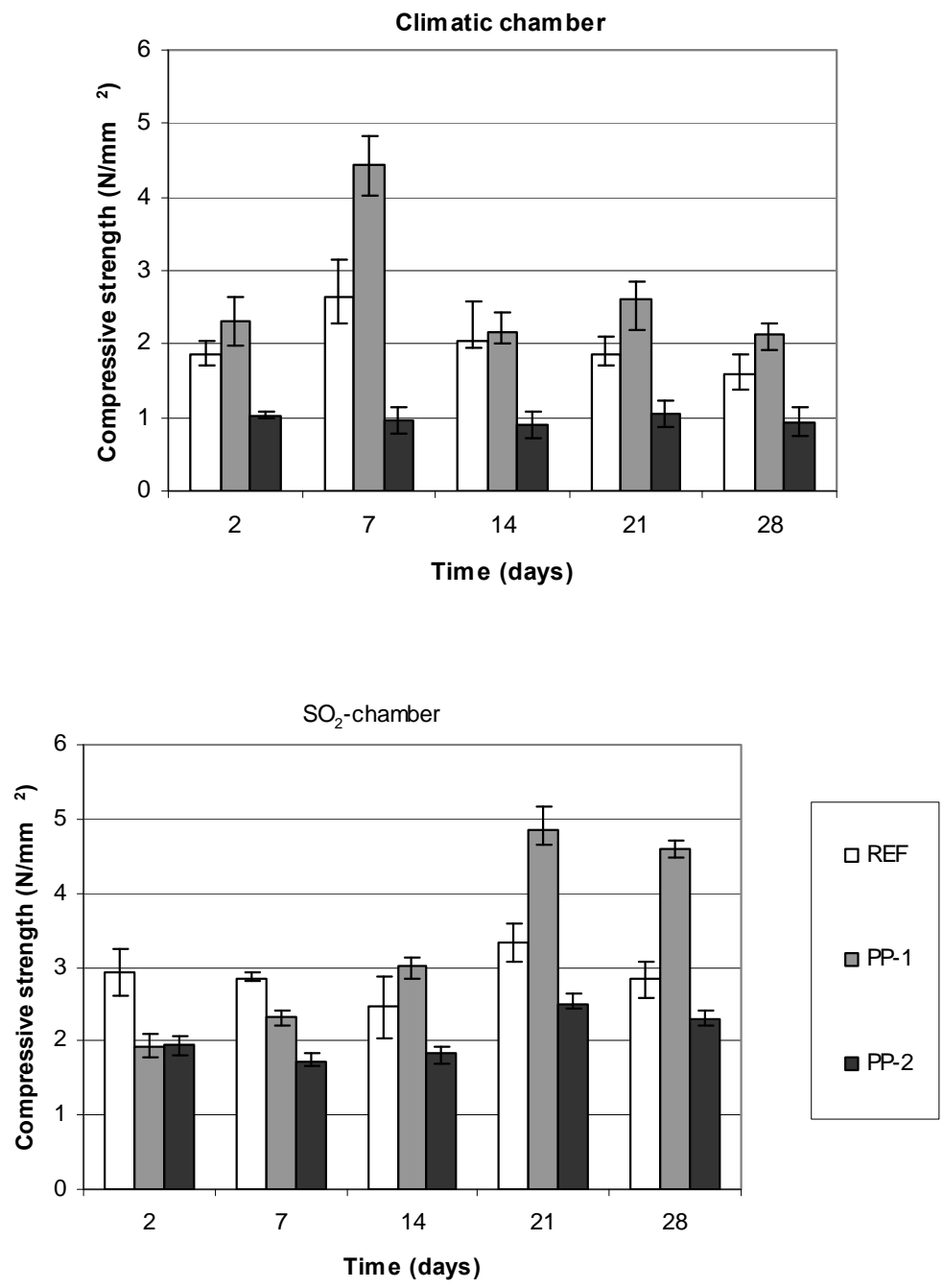

a)

b)

Figure 14. Compressive strengths of mortars with fibre after being subjected to different environments. 


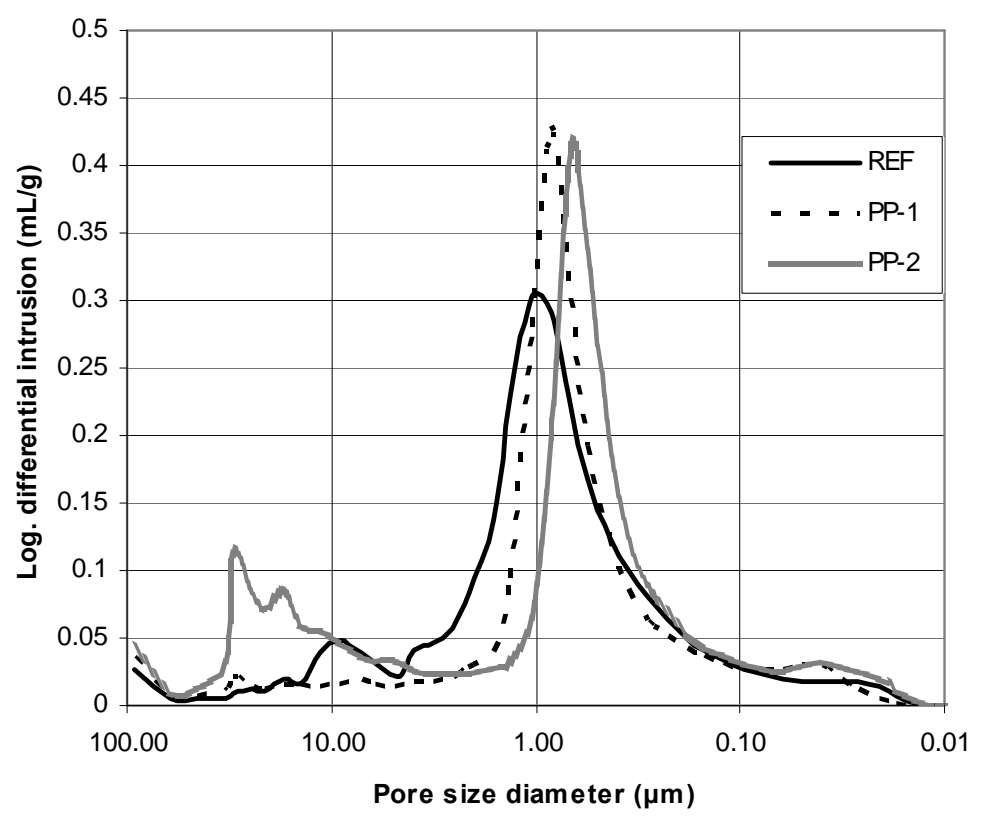

a)

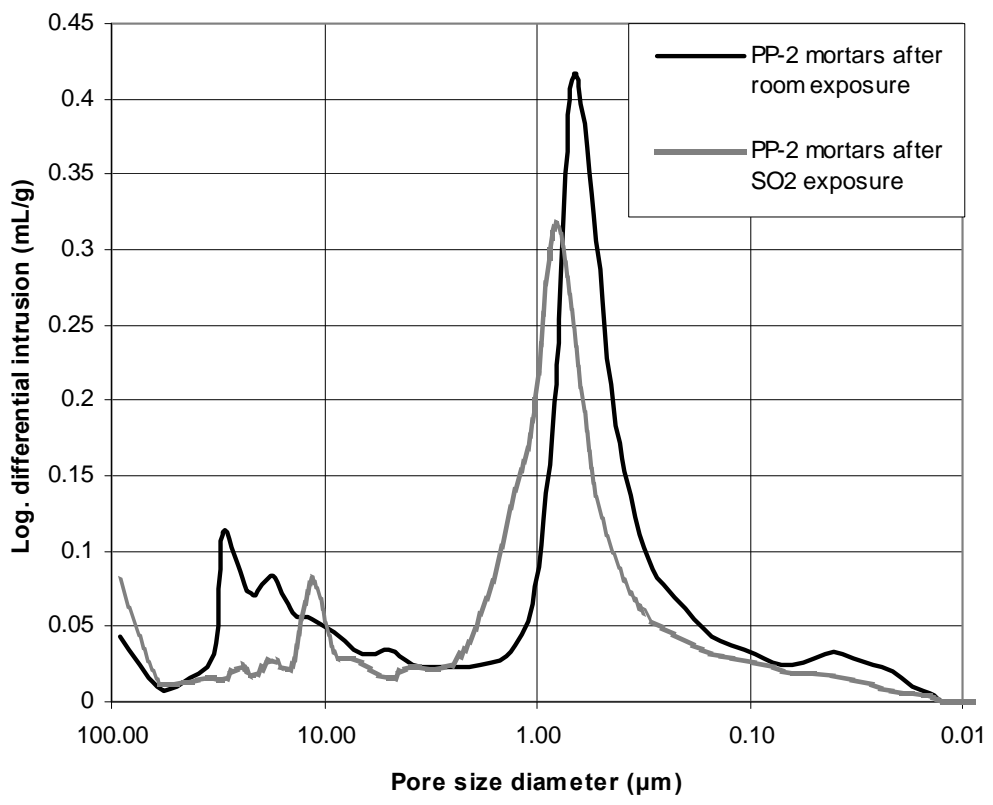

b)

Figure 15. Pore size distributions of samples: a) pore size distribution of reference mortar, samples with low dosage of fibre (PP-1) and samples with high dosage of

fibre (PP-2) hardened in room conditions; b) pore size distribution of mortars modified with high dosage of fibre, after being exposed to room conditions and after being exposed to $\mathrm{SO}_{2}$-chamber. 


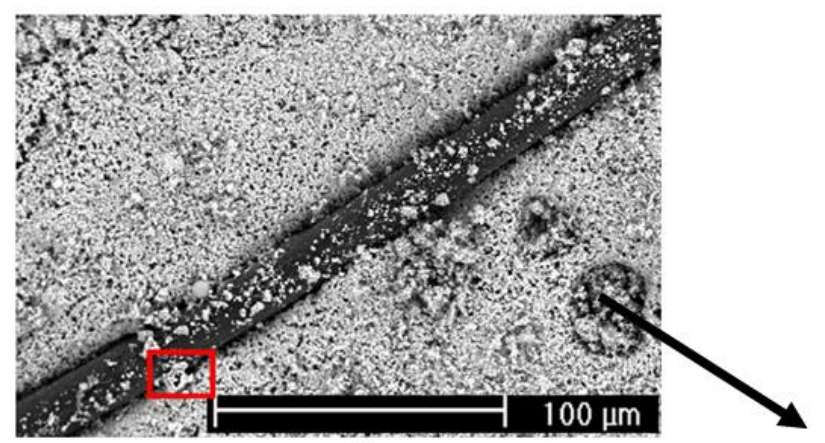

a)

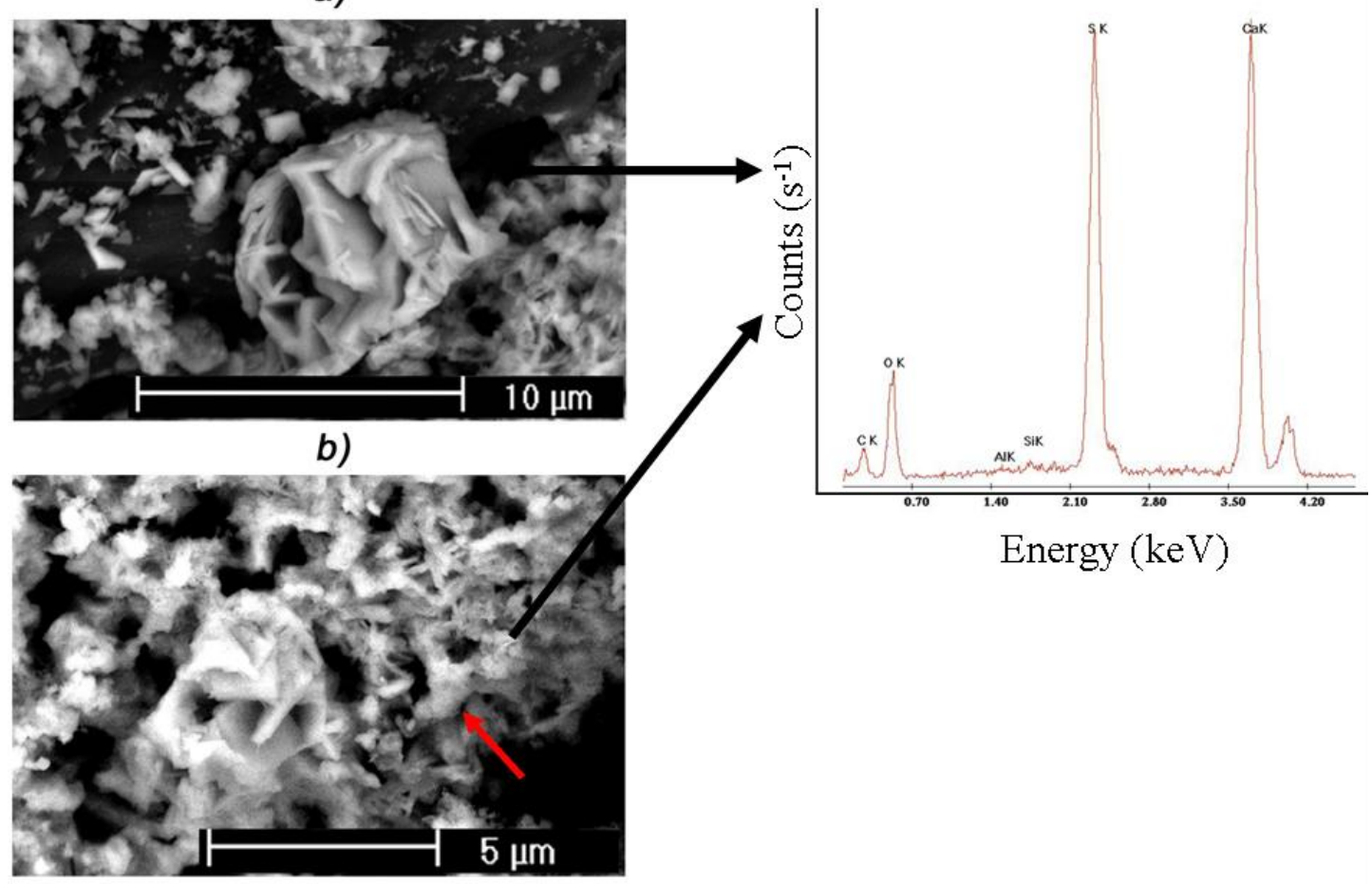

c)

Figure 16. SEM images of PP-2 mortars's surface after being exposed to $\mathrm{SO}_{2}$ chamber: a) fibre thread in the specimen surface; b) detail of the previous image (red rectangle), showing plate-like crystals of gypsum; c) image of a different zone of the surface, where some plate-like crystals can be observed in the middle of the picture, and some rough spherical crystals of calcium sulphite hemihydrate (one of them fixed with an arrow) are also present. 


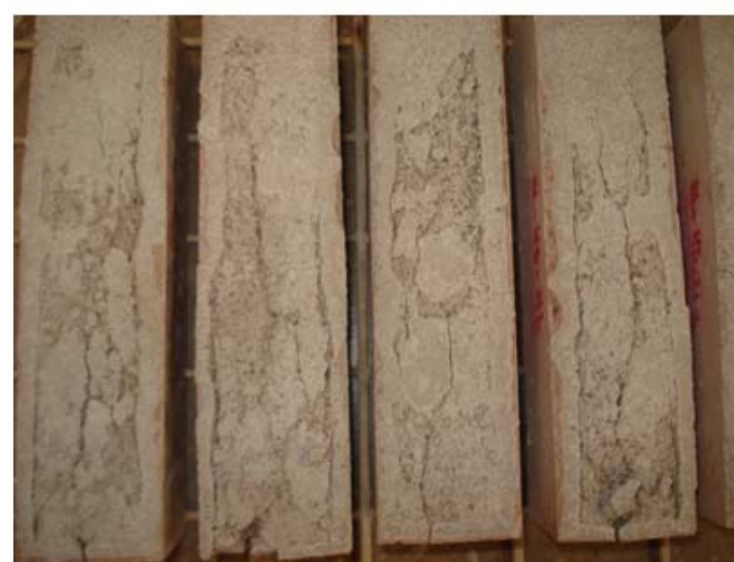

a)

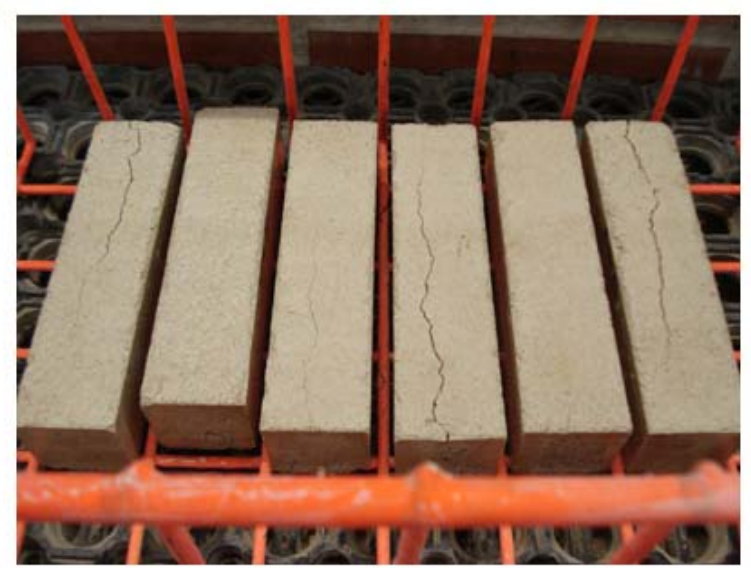

b)

Figure 17. Mortars during freezing-thawing cycles: a) REF mortar after 4 cycles, with clear signs of deterioration, degree 4 of alteration; b) PS mortars after 4 cycles, clearly less affected than REF mortars, degree 2-3. 

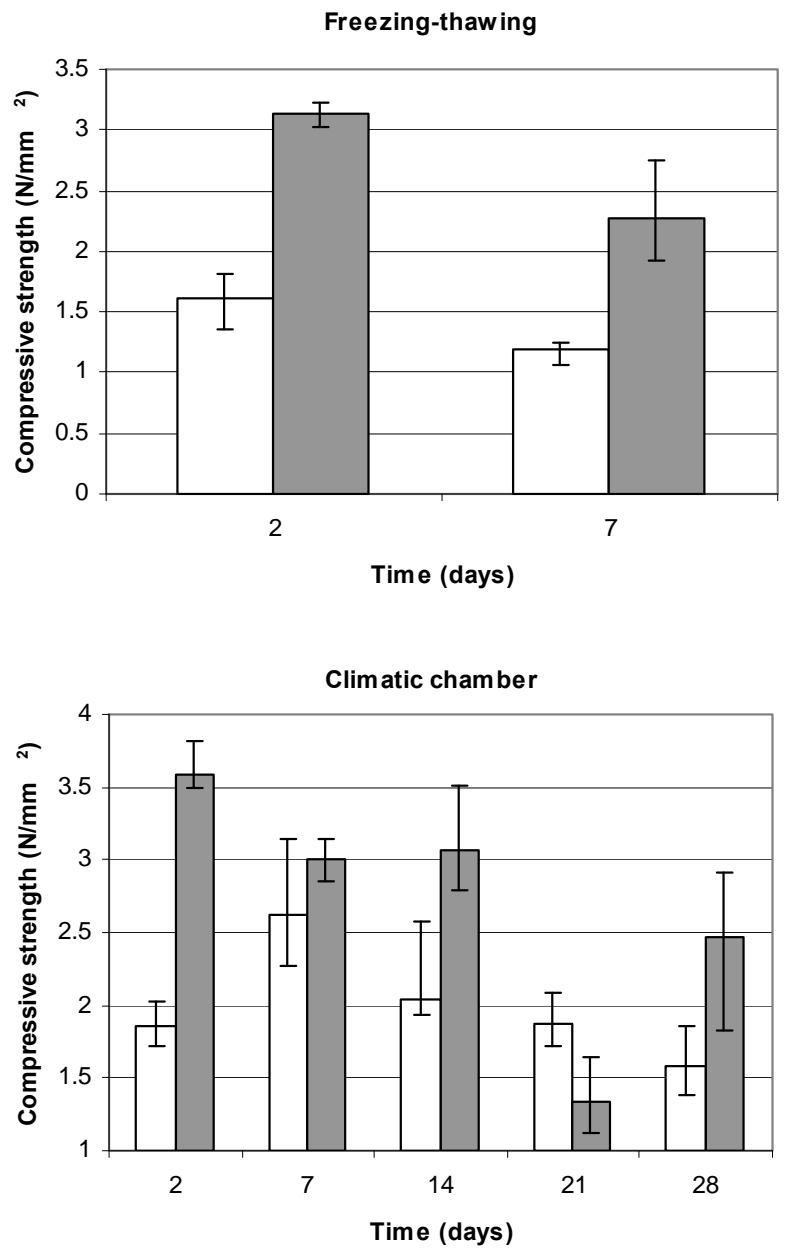

a)

b)

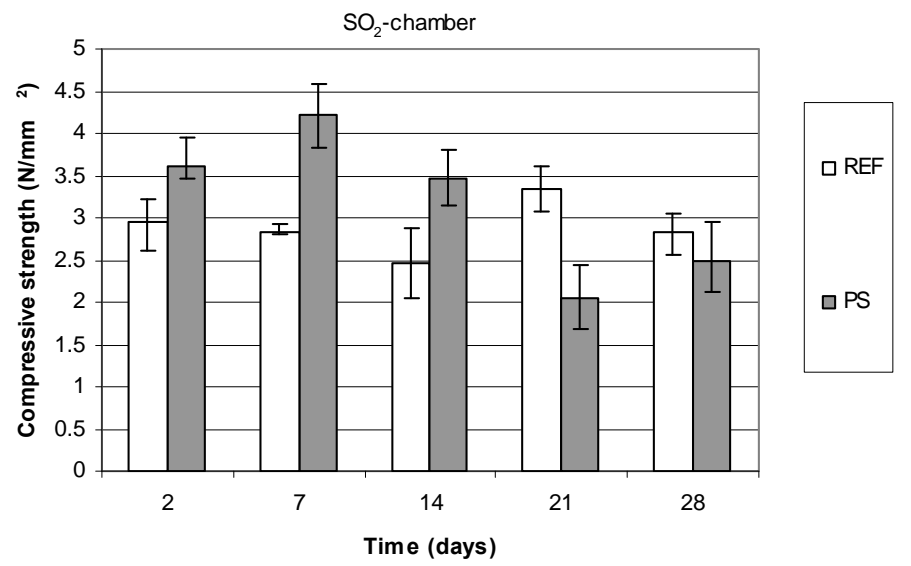

c)

Figure 18. Mechanical strengths of mortars with starch under different conditions. 


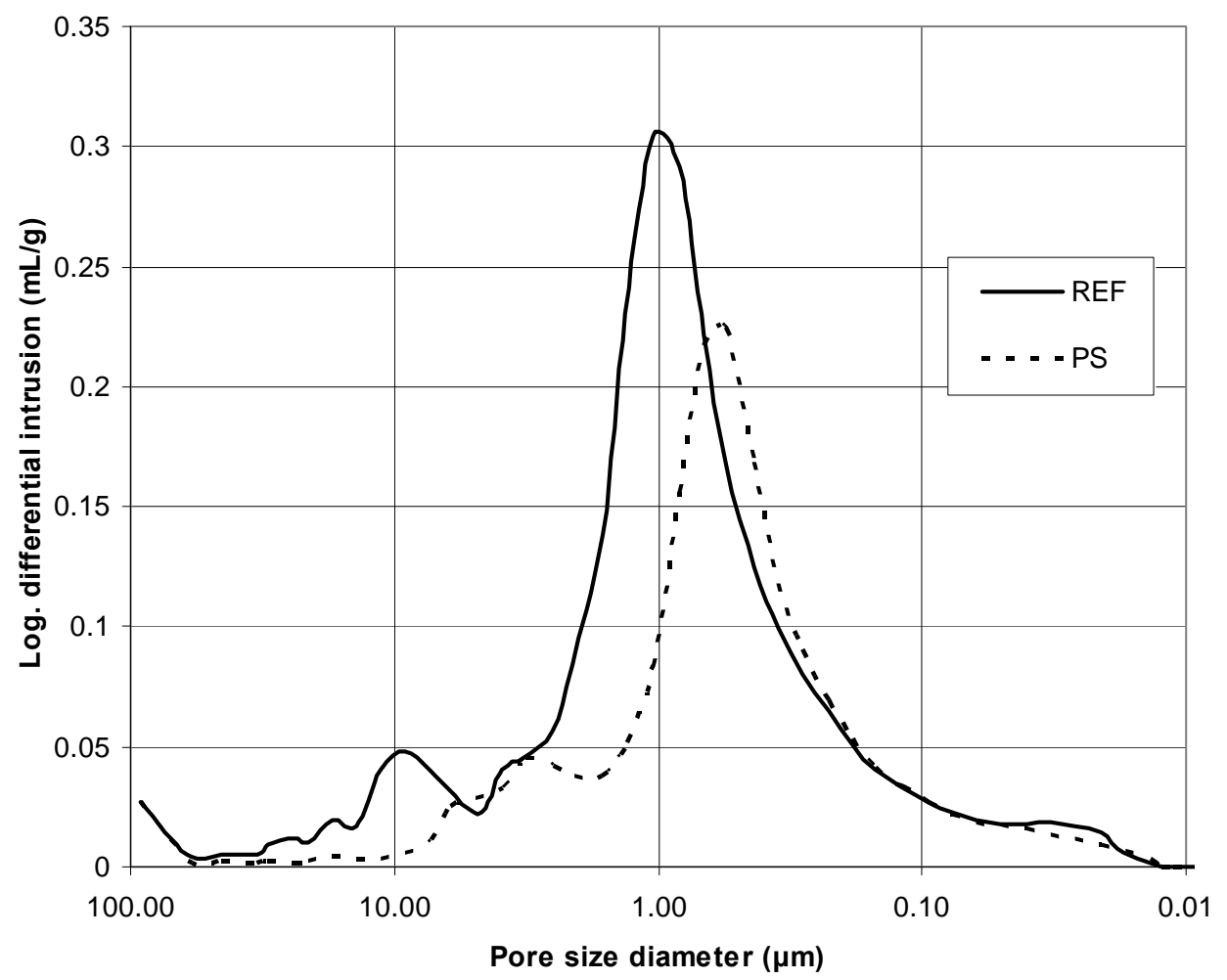

a)

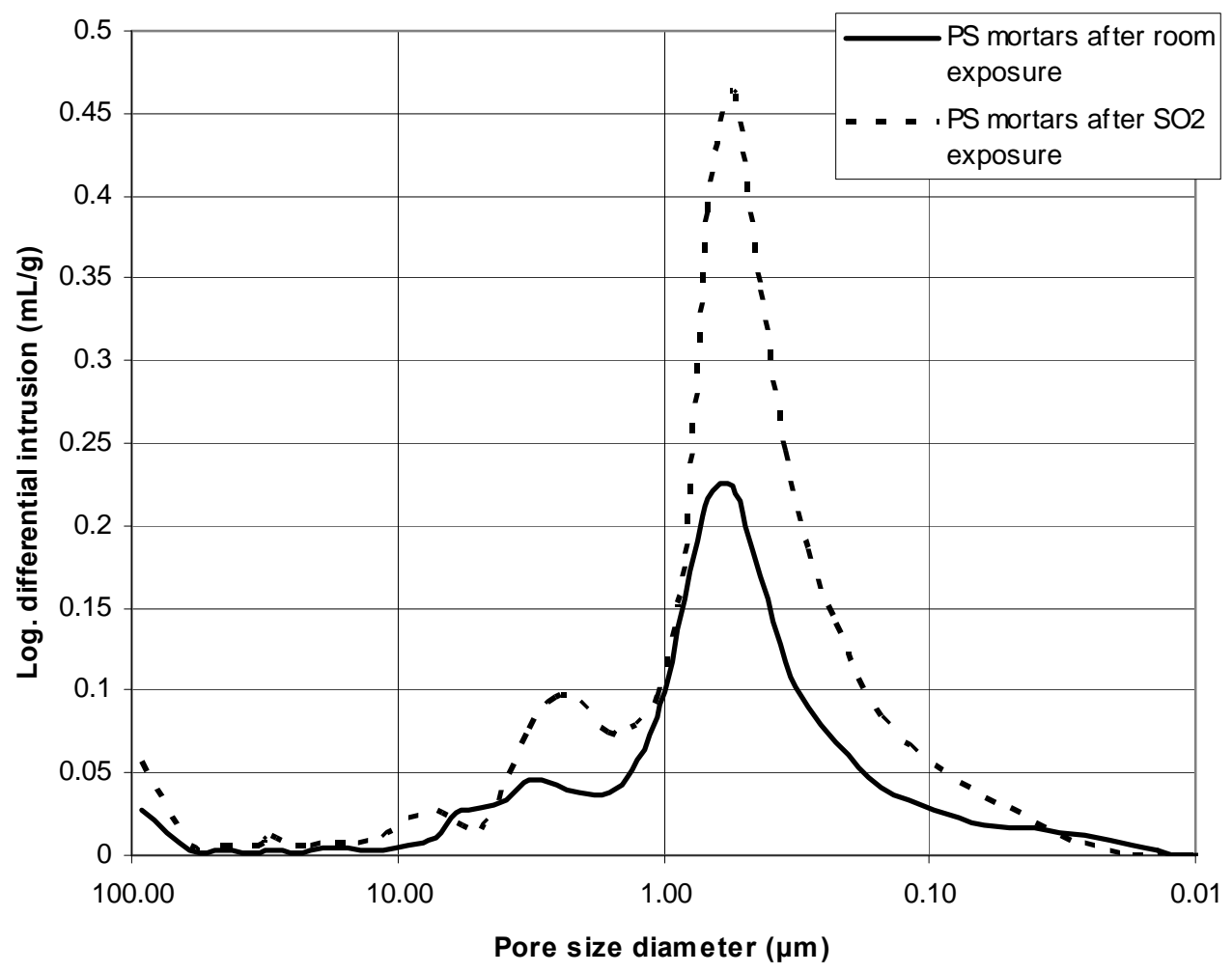

b) 
Figure 19. a) Pore size distribution of control material and mortar modified with starch (after indoor exposure); b) pore size distribution of mortar with starch after room exposure and after $\mathrm{SO}_{2}$ exposure.

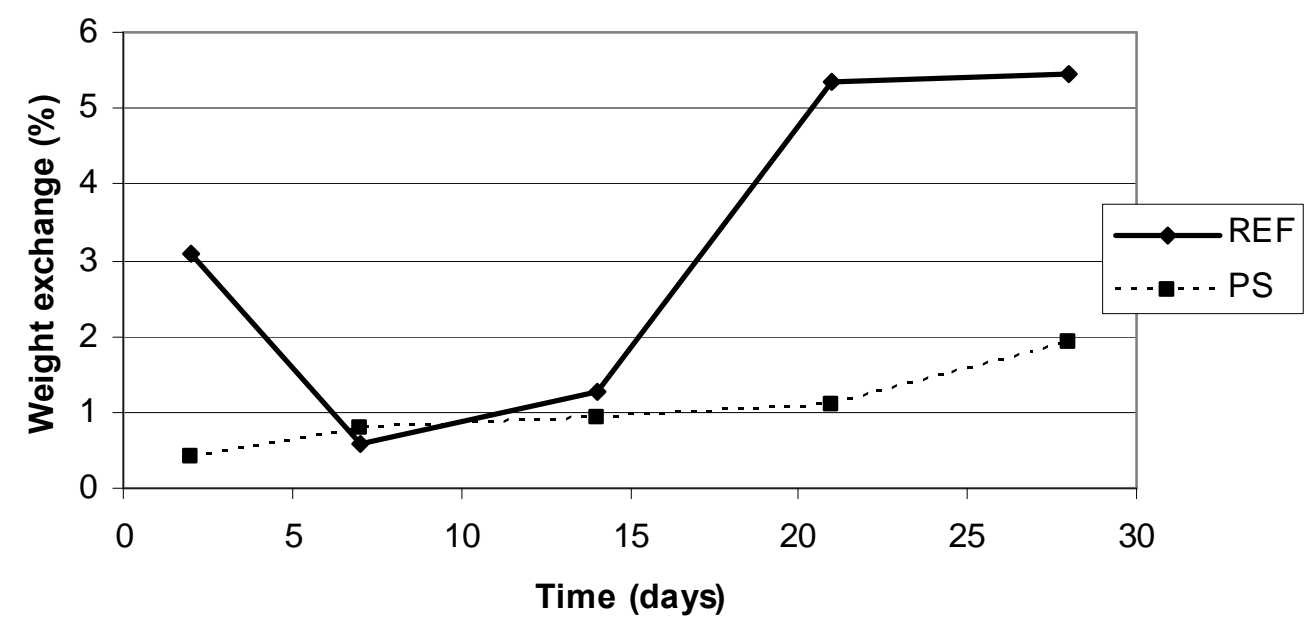

Figure 20. Weight change of mortars modified with starch after exposure in climatic chamber. 